NBER WORKING PAPER SERIES

\title{
THE ROLE OF SALES AGENTS IN INFORMATION DISCLOSURE: EVIDENCE FROM A FIELD EXPERIMENT
}

\author{
Hunt Allcott \\ Richard Sweeney \\ Working Paper 20048 \\ http://www.nber.org/papers/w20048
NATIONAL BUREAU OF ECONOMIC RESEARCH
1050 Massachusetts Avenue
Cambridge, MA 02138
April 2014

Previously circulated as "Information Disclosure through Agents: Evidence from a Field Experiment." We thank Judd Boomhower, Lucas Davis, Stefano DellaVigna, Carolyn Fischer, Ginger Jin, Katy Milkman, Erich Muehlegger, David Rapson, Imran Rasul, Jim Sallee, and seminar participants at the ASSA Annual Meeting, Berkeley, Harvard, and the Program on Workable Energy Regulation conference for helpful comments. Alex Cheng provided exceptional research assistance, and Larry Ehrhardt programmed the experiment website. Our legal agreement does not allow us to identify the Retailer or its employees, but we thank sales agents and management, in particular PC and JW. Customer follow-up survey protocols and Stata code to replicate the analysis is available from Hunt Allcott's website. We are grateful to the Sloan Foundation for funding this experiment and our related research on the economics of energy efficiency. The views expressed herein are those of the authors and do not necessarily reflect the views of the National Bureau of Economic Research.

NBER working papers are circulated for discussion and comment purposes. They have not been peerreviewed or been subject to the review by the NBER Board of Directors that accompanies official NBER publications.

(C) 2014 by Hunt Allcott and Richard Sweeney. All rights reserved. Short sections of text, not to exceed two paragraphs, may be quoted without explicit permission provided that full credit, including $(\subset$ notice, is given to the source. 
The Role of Sales Agents in Information Disclosure: Evidence from a Field Experiment Hunt Allcott and Richard Sweeney

NBER Working Paper No. 20048

April 2014, Revised March 2015

JEL No. D04,D12,L15,L51,L68,Q48

\begin{abstract}
$\underline{\text { ABSTRACT }}$
With a large nationwide retailer, we run a natural field experiment to measure the effects of energy use information disclosure, customer rebates, and sales agent incentives on demand for energy efficient durable goods. While a combination of large rebates plus sales incentives substantially increases market share, information and sales incentives alone each have zero statistical effect and explain at most a small fraction of the low baseline market share. Sales agents strategically comply only partially with the experiment, targeting information at more interested consumers but not discussing energy efficiency with the disinterested majority. These results suggest that at current prices in this context, seller-provided information is not a major barrier to energy efficiency investments. We theoretically and empirically explore the novel policy option of combining customer subsidies with government-provided sales incentives.
\end{abstract}

Hunt Allcott

Department of Economics

New York University

19 W. 4th Street, 6th Floor

New York, NY 10012

and NBER

hunt.allcott@nyu.edu

Richard Sweeney

Harvard Kennedy School

rich_sweeney@hksphd.harvard.edu 


\section{Introduction}

Consumers often learn about new or higher-quality products from firms, and in theory, information problems can be ameliorated as sellers of relatively high-quality products inform consumers of their beneficial attributes 1 In many cases, however, barriers to information transmission can cause a failure of "unraveling," and imperfect information could reduce demand for high-quality products. In these situations, regulators may be able to increase welfare by mandating or otherwise inducing information disclosure, subsidizing quality, or even setting minimum quality standards. Before intervening, however, a regulator might want additional information: How successful are firms at providing information? How well-informed are consumers about new products and their attributes?

Every year, Americans purchase $\$ 361$ billion in energy-using durable goods such as cars and air conditioners and spend $\$ 570$ billion on energy for those goods (BLS 2014). Regulators intervene in durable goods markets by mandating energy use information disclosure and by encouraging additional marketing of energy efficiency through initiatives such as the Energy Star Retail Partner program. Imperfect information is also commonly used to justify extensive subsidies for energy efficient goods, as well as minimum energy efficiency standards 2 Despite the importance of imperfect information in the energy policy debate, however, there is limited evidence on how energy cost information disclosure affects demand for durable goods. Dranove and Jin's (2010) review of the information disclosure literature discussed zero studies related to energy efficiency, although we discuss below how this literature has recently received more attention.

We study water heaters, which are interesting and important precisely because they are so mundane. Consumers rarely think about their water heater until it breaks unexpectedly, at which point they want to replace it quickly, with limited time for search and information acquisition. Consumers rarely discuss water heaters with their friends, meaning that retailers play a pivotal role in guiding purchases. At average product lifetimes and usage rates, purchasing an energy efficient "Energy Star" natural gas water heater instead of a standard model is an investment with 13-18 percent return - and this is before the generous subsidies offered by many local utilities. Despite this, the Energy Star market share is only about 3 percent at the retailer we study. These choices are expensive: water heating is the second largest home energy use in the U.S. (DOE 2009), consuming about $\$ 300$ in energy annually per household, or about $\$ 29$ billion per year nationwide.

Motivated by these issues, we carried out a natural field experiment with a large nationwide retailer that sells water heaters and many other goods. We worked at the Retailer's call center,

\footnotetext{
${ }^{1}$ See Grossman (1981), Milgrom (1981), and Viscusi (1978).

${ }^{2}$ There are many examples. The American Council for an Energy Efficient Economy argues that minimum efficiency standards are merited for several reasons, including "rush purchases when an existing appliance breaks down, providing no time to comparison shop" (Nadel 2011). The Regulatory Impact Analysis for the increase in the Corporate Average Fuel Economy standard for 2012 to 2016 argues that even without counting the value of externality reductions, the regulation increases consumer welfare, perhaps because consumers are not correctly informed about the value of fuel economy (NHTSA 2010, page 2). The Regulatory Impact Statement for Australia's ban on energy inefficient lightbulbs argues that "information failures" help to justify that policy (DEWHA 2008, page vii).
} 
which sells about 45,000 water heaters each year. More than 20,000 callers were randomly assigned between treatments in which sales agents were instructed to provide energy cost savings information and/or offer customer rebates for Energy Star models. We also offered $\$ 25$ sales incentives for agents who sold Energy Star on randomly-selected calls, and we crossed these incentives with the customer rebates.

A crucial feature of our experiment is that the seller's interactions with customers are intermediated by sales agents. This is not uncommon: consumers learn about life insurance, mutual funds, and many consumer goods at least partially through agents. In our setting, sales agent behavior is important for two reasons. First, it directly determines the Retailer's ability to market Energy Star products: if sales agents don't provide information on a call, callers will likely remain uninformed. Second, in equilibrium, it is indirectly informative about consumers' responsiveness to information: given that information disclosure takes time and focus away from other sales tasks, if consumers are not interested in information, agents will not provide it. To document sales agent behavior, our research team independently audited more than 2,000 phone calls, quantifying the interactions between agents and consumers. Our ability to observe agent behavior, instead of simply the equilibrium outcome of attempting to disclose information, is one feature that distinguishes this paper from previous work.

There are several reasons to expect that the treatments could substantially increase Energy Star market share. Because consumers are thought to be poorly informed about water heater features, they often accept sales agents' recommendations about what model to purchase. The $\$ 100$ customer rebate increases the average consumer's return on investment in an Energy Star model to 28-37 percent, and when combined with additional subsidies available from many local utilities, our $\$ 100$ rebate brings the incremental purchase price of the Energy Star model close to zero. The $\$ 25$ sales incentives are equal to two times agents' fixed hourly wage and are ten times larger than their usual sales incentive.

Against this backdrop, our results are surprising. Our audits show that agents comply with delivering the information and rebates on only about one-fifth of calls. Information has zero statistical effect on demand, and confidence intervals rule out that demand increases by more than 4.9 percentage points on calls when the information is delivered and the consumer is considering a substitutable model. While this bound is large relative to the baseline Energy Star market share, it suggests that the market share would still be very low even if agents informed all consumers. The $\$ 100$ customer rebates do increase Energy Star purchases, however, and the combination of a $\$ 25$ sales incentive and $\$ 100$ customer rebate appears to have particularly strong complementary effects. This last result suggests one potential policy implication: when addressing market failures that might distort energy-using durable good purchases, policymakers may wish to consider also incentivizing sales agents instead of only subsidizing consumers' purchases.

We show that agents preferentially market Energy Star to consumers with higher latent demand 
for Energy Star. Furthermore, on calls with the $\$ 25$ sales incentive but no experimental customer rebate and no explicit direction to deliver an informational script, agents exert very little effort to sell Energy Star models. Along with the small information effect, these results suggest that agents' non-compliance is better described as "strategic" instead of "shirking": agents don't inform consumers about Energy Star because they know that at the retailer's base price, most consumers are not interested in the product once informed.

There are two potential explanations for why the Retailer's attempts at information disclosure did not increase Energy Star demand. First, consumers may tend to be unaware of Energy Star and underestimate its benefits, but sales agents may not be able to address this because their "disclosure technology" is limited: they work in time-constrained sales interactions and may have a perceived lack of credibility when promoting a higher-priced model. Second, consumers might already be relatively well-informed about Energy Star availability and benefits, and most choose not to buy because they don't think that the reduced energy use is worth the incremental upfront cost. These two explanations have very different implications for whether regulators should intervene to provide information or otherwise encourage energy efficiency.

We carried out an extensive set of customer follow-up surveys to shed light on these two explanations. On the one hand, there is evidence that consumers are confused: even when "Energy Star" is precisely defined, 52 percent of consumers report believing that they had bought an official Energy Star model, while only 2.1 percent actually had. Of the consumers who thought they had not bought Energy Star, 15 percent reported that this was because they were not aware that there was an Energy Star option. On the other hand, the great majority of consumers were aware of Energy Star, and their foremost reason for not purchasing was that the price was too high. Furthermore, while there is wide dispersion of beliefs, the average consumer actually overestimates the potential energy cost savings from Energy Star. While the survey results are not as conclusive as the experimental results, they at least suggest that lack of awareness and cost savings information are not the primary barriers to energy efficiency in this context.

We also include a simple theoretical model which helps to motivate the experiment and interpret results. The model is a two-firm version of Grossman and Shapiro's (1984) analysis of informational advertising in a Hotelling spatial model. We extend this framework to include two goods, a base good and a "high-quality" (energy efficient) good, and nest within the firm a set of optimizing sales agents who disclose information at convex cost. The model highlights the importance of equilibrium interactions between the firm's management, sales agents, and consumers: because information provision is costly, sales agents will not provide information if consumers are unresponsive, and consumers will be unresponsive when the firm sets a relatively high price for the high-quality good. When the firm lowers the price of the high-quality good, however, consumers become more interested in the product, and agents exert more effort in marketing it. The model also helps to clarify the policy relevance of the experiment by formalizing how minimum quality (energy efficiency) 
standards are more likely to increase welfare if the high-quality good is more beneficial and if experimental results show that it is difficult for firms to inform consumers of this. Furthermore, the model formally considers government-provided sales agent incentives, showing that they can increase welfare if firms under-provide information relative to the social optimum and firms are not able to "undo" the government-provided incentive in equilibrium.

The remainder of this section discusses related literature. Section 2 provides an overview of the water heater market, and Section 3 presents the theoretical model. Section 4 details the experimental design and data. Section 5 presents the empirical results, and Section 6 concludes.

\section{$1.1 \quad$ Related Literature}

Our study is broadly connected to several different literatures. Most immediately, our study is related to the literature on information disclosure, as reviewed by Milgrom (2008) and Dranove and Jin (2010). Empirical papers on the effects of information disclosure include Choi, Laibson, and Madrian (2010), Duarte and Hastings (2012), and Duflo and Saez (2003) on financial decisions, Greenstone, Oyer, and Vissing-Jorgensen (2006) on securities, Bhargava and Manoli (2013) on takeup of social programs, Jin and Sorensen (2006), Kling et al. (2012), and Scanlon et al. (2002) on health insurance plans, Jin and Leslie (2009) on restaurant hygiene, Pope (2009) on hospitals, Bollinger, Leslie, and Sorensen (2011) and Luo et al. (2012) on health and nutrition, Dupas (2011) on HIV risk, Figlio and Lucas (2004) and Hastings and Weinstein (2008) on school choice, and many others.

Closely related is the literature that studies the effects of energy-related information. There are a number of papers in this domain that differ from ours in only one respect. Some studies analyze the effects of energy use information disclosure on stated preferences or other proxies for actual purchases of durable goods, including Davis and Metcalf (2014), Deutsch (2010a, 2010b), Newell and Siikamaki (2013), and Ward, Clark, Jensen, Yen, and Russell (2011). Some studies either use observational data (Kallbekken, Saelen, and Hermansen 2013) or randomly assign a very small number of units (Anderson and Claxton 1982). There are other large-sample RCTs that study how peer energy use comparisons affect purchases of durable goods, including Allcott and Rogers (2014), Brandon, List, Metcalfe, and Price (2014), and Herberich, List, and Price (2011), but this social information is conceptually distinct from information about the durable good itself. Also related is Houde's (2014a) analysis of the Energy Star label and other studies of how various kinds of information affect total household energy use, such as Allcott (2011), Dolan and Metcalfe (2013), Jessoe and Rapson (2014), and others. Along with Allcott and Taubinsky (2015), our paper is slightly different in that it uses large sample RCTs to study how providing information about a durable good's energy use affects actual purchases of that good. This particular question is important given the regulatory resources that go into durable good energy use disclosure programs and given the costly energy efficiency standards and subsidies that are partially predicated on the 
idea that consumers remain imperfectly informed when purchasing durable goods. Furthermore, our paper is substantially conceptually different from the rest of the energy information literature due to its focus on a situation where the information provision process is intermediated by sales agents.

Our experiment is also related to studies of behavior by sales agents and advisers, including field experiments by Anagol, Cole, and Sarkar (2013), Mullainathan, Noeth, and Schoar (2012), and Nagin et al. (2002), as well as theoretical analyses by Hoffman, Inderst, and Ottaviani (2013) and Inderst and Ottaviani $(2009,2012)$. This literature largely focuses on information asymmetries between sales agents and consumers or alternatively on agency problems between firm managers and workers. While these issues could be at play in our context, we do not focus on them. In our model, the firm's inability to observe sales agent behavior does not reduce profits, and agents give consumers correct information about the product. Instead, we highlight agents' imperfect and differential compliance with the experiment. This angle is comparable to findings by Duflo, Gale, Liebman, Orszag, and Saez (2006) that tax preparation professionals have different levels of success in encouraging tax filers to contribute to retirement accounts. Our experimental tests of sales force incentives connect us to the sales force management literature (see Mantrala et al. (2010) for a review and Chan, Li, and Pierce (2014) for a recent example), the "insider econometrics" approach to studying employee compensation and management practices (see Ichniowski and Shaw (2003) for an earlier review), and to "process" field experiments in strategy research (Chatterji et al. 2015).

A key innovation relative to the literatures on information disclosure and employee incentives is that we highlight the interaction between consumer and firm behavior in equilibrium. Much of the recent empirical work on information disclosure studies consumer responses to information that is experimentally provided with certainty or disclosed by firms under mandate, which isolates consumer behavior independent of the firm. Conversely, much of the employee incentives literature focuses on worker behavior in isolation of the consumer. For example, Ashraf, Bandiera, and Jack (2012), Barankay (2012), Bandiera, Barankay, and Rasul (2005, 2007, 2009, 2010), Larkin (2013), Lazear (2000), Shearer (2004), and others focus on how employees respond to different types of incentives, but these responses do not meaningfully depend on behavior by the firm's customers. By contrast, a central feature of our setting is that the firm's ability to motivate its sales agents to promote a product depends crucially on consumer interest in that product, which is in turn determined by the firm's pricing decisions. A handful of other papers have highlighted other types of equilibrium interactions between the supply and demand sides of the market for energy efficiency, including Fischer $(2005,2011)$ and Houde (2014b). 


\section{Market Overview}

\subsection{The Water Heater Market}

There are over 100 million water heaters currently in use in the United States, approximately one per household $!^{3}$ The typical water heater remains in use for 13 years (DOE 2010), which translates into a seven to eight percent replacement rate per year. Non-replacement sales vary with the state of the new housing market, but they historically represent 18 percent of total sales. "Storage" water heaters, where water is stored hot as opposed to heated up on demand, make up 96 percent of the market. In 2012, there were 7.69 million residential storage water heaters sold in the United States, 3.96 million (51 percent) of which are fueled by natural gas (AHRI 2013), while the rest use electricity.

Water heater manufacturing is highly concentrated, with the top three producers (A.O. Smith, Rheem, and Bradford White) supplying 96 percent of all residential water heaters in 2008. Approximately half of all units are sold through wholesale distributors; of these, 87 percent are purchased and installed by plumbers. The remaining half of all units are purchased through retail channels such as our partner Retailer. In 2010, the Retailer had a 9 percent share of the retail market, third behind two other retailers that had 23 and 19 percent shares. Thirty percent of the Retailer's sales are made through the call center where our experiment takes place, while the remaining 70 percent are made in physical retail establishments. Our sample thus includes a small but non-trivial share of all water heaters sold in the United States over the study period.

\section{$2.2 \quad$ Water Heater Attributes}

Water heaters are a convenient product to study because they are differentiated only on a few dimensions. Key characteristics are:

- Fuel type: natural gas, propane, or electric. Consumers' choices depend on what fuels are available in their houses, so choices along this dimension are effectively exogenous. We limit our study to natural gas and propane water heaters, as there are no Energy Star electric models. Less than one percent of sales in the sample were propane-fueled models.

- Storage tank size. This determines the amount of hot water available at any time. Residential tank sizes range from 30 to 80 gallons. In our sample, 90 percent of sales are either 40 or 50 gallons.

- Warranty length. The Retailer offers models with warranty lengths of 3,6, 9, and 12 years. Models with longer warranties are typically constructed differently, using additional or improved anode rods to delay or fully prevent rusting.

\footnotetext{
${ }^{3}$ DOE (2010) provides an overview of the United States water heater market; this is the source of most of the statistics presented here.
} 
- Tank height. Some consumers need to install water heaters in basements with low ceiling heights. In our sample, about eight percent of sales are "short" models, while the rest are standard height.

- Nitrogen oxide emissions. In some areas, in particular the San Francisco Bay Area and southern California, air quality regulations require consumers to purchase "low NOx" water heaters, which have different natural gas combustion chambers that produce less nitrogen oxide.

- Power venting. Typical natural gas water heaters vent hot combustion gases out of the house through a vertical chimney. When this is not possible, a power vent water heater is required to push the gases outside through a horizontal pipe.

- Mobile home designs. The Retailer sells water heaters specifically designed for mobile homes; these comprise less than one percent of our sample.

- Energy use. We discuss this below.

\subsection{Water Heater Energy Use and the Energy Star Technology}

Each model's energy use is tested at an independent laboratory using test protocols defined by the U.S. government. Test results are used for the FTC Energy Guide labels, or "yellow tags," which are energy use information labels that provide estimated annual energy costs based on national average usage and energy prices. The yellow tags report total energy costs across all fuels used, which for the Energy Star models includes both natural gas and electricity. By law, yellow tags must be displayed on water heaters in a showroom, and the Retailer's website also includes PDFs of the yellow tag next to each model's description. Thus, while many consumers may not see or attend to energy cost information, it is easily verifiable. Of course, each household's actual energy costs may differ from the average due to utilization rates, climate, and other factors.

The energy use test protocols are also used to calculate statistics called Energy Factors, which represent the share of energy input into the water heater that is transformed into hotter water instead of otherwise dissipated. To qualify for Energy Star status, a natural gas water heater must achieve an Energy Factor of 0.67 or above, compared to the standard 0.59.

During our study period, the Retailer sold four natural gas Energy Star models. Two are modified versions of their standard 40 and 50 gallon models with 6-year warranties. To improve energy efficiency, the manufacturer adds another inch of insulation around the tank and uses electric ignition instead of a continuously-burning pilot light. To accommodate electric ignition, the Energy Star models must be plugged in to a power outlet, and they consume a small amount of electricity. They also have electronic thermostats and a more advanced flue damper that opens and closes depending on whether gas is currently being burned. These differences only affect energy use 
and have no material impact on unit performance, and there are no other differences between the standard and Energy Star 6-year warranty models. (Of course, consumers may attach other connotations to the Energy Star label, and as we mention below, local in-stock availability is an additional differentiator.)

The other two Energy Star models are 40 and 50 gallon premium models with 12-year warranties. The premium models have the same amount of insulation as the standard 12-year models; they achieve higher energy efficiency through electric ignition and other modifications to the combustion process. The premium Energy Star models also differ from the standard 12-year models on other dimensions that make them generally higher-quality.

Table 1 presents information on these four Energy Star models and how they compare to their closest substitutes. Standard models cost $\$ 400$ to $\$ 700$, not including installation. According to the yellow tags, standard models use about $\$ 300$ worth of energy each year, meaning that lifetime cost is much larger than upfront purchase price. Energy Star models save about $\$ 30$ per year. Because the 6-year warranty models are very close substitutes except for purchase price and energy cost, the 13 and 18 percent internal rates of return are reasonable approximations of the expected monetary net benefits of Energy Star. By contrast, the 12-year Energy Star model also has other premium features, so 1 and 3 percent internal rates of return do not capture the full benefits of the premium model.

Because of the fixed costs of developing, certifying, and manufacturing a unique model, manufacturers do not produce Energy Star versions of each standard water heater. In particular, the manufacturer that supplies the Retailer does not make mobile home or propane Energy Star models. Because of the fixed costs of procuring and stocking each model, the Retailer also does not carry all the Energy Star models that the manufacturer offers. The Retailer does not carry the manufacturer's short tank size or low-NOx Energy Star models. Because consumers are effectively unable to substitute across these features, we define a subset of "substitutable" models that includes all Energy Star and non-Energy Star natural gas tank water heaters except for low-NOx, short tank height, mobile home, power vent and propane models.

\subsection{The Sales Process}

According to DOE (2010), 35-40 percent of replacement purchases nationwide arise suddenly due to complete unit failure, typically when water rusts through the steel tank and escapes onto the floor. Our follow-up customer surveys show that 83 percent of purchases in our sample were due to unexpected breaks instead of planned replacements. Because most people don't like cold showers, consumers typically want to replace their water heater within 24 hours if possible. This hurry has several implications. First, consumers have not saved money in anticipation of a large expenditure, so they may be especially price sensitive. Second, consumers tend to prefer models that are in stock locally and can thus be installed quickly. Because sales volumes are lower, the Retailer stocks 
Energy Star water heaters at fewer locations than its standard models. Third, consumers make little time to acquire information about different types of water heaters and their attributes.

A quote from our survey of the Retailer's sales agents nicely summarizes these issues: "Customers that were shopping ahead [i.e. not responding to an unexpected unit failure] seemed to be making more educated decisions ... they were more inclined to use the Energy Star water heaters as item they wanted their quote for. I feel that whenever there was not such a sense of urgency ... customers were in a position to spend more on a better water heater and also able to wait for it to be ordered."

When customers call the Retailer's water heater call center, sales agents have significant influence over their decisions. Some callers have done background internet research and think they know what model they want before calling, while the majority know only that they need a new water heater. Agents work with these callers to determine which model is best for them based on the attributes discussed above, such as fuel type, ceiling height, local low-NOx regulations, and appropriate tank size.

Before the experiment started, we called the Retailer's call center a number of times, acting as "mystery shoppers." We found that the Retailer's sales agents have been successfully trained to look up Energy Star rebates offered by local utilities, discuss Energy Factors, and discuss information on yellow tags. Unless the caller asks about energy efficiency, however, agents never discussed the issue with us, because information disclosure is costly. As one agent wrote on our survey, "I would say about 90 percent of our customers only care about how cheaply can they get away with the purchase of a water heater." Sharing extraneous information increases call times, and many call centers evaluate agents on call times in order to keep labor costs low. Longer call times can reduce customer satisfaction and increase the probability that the customer gets distracted and does not complete the sale.

These features of the water heater sales process motivated our experiment: perhaps Energy Star sales are low because consumers are unaware of the product and its benefits, and agents' influence over consumers could be leveraged to increase awareness. Notwithstanding, this discussion also makes clear that informing consumers is costly. In the next section, we present a model that captures these issues.

\section{$3 \quad$ Experimental Design and Data}

\subsection{Sales Associates and the Sales Process}

The Retailer's water heater division operates two call centers. There are 77 sales agents who take at least one call during our sample period. These sales agents sell only water heaters, not other goods. The agents report to Team Managers, who in turn report to Shift Managers, who report to the call center manager. Agents make between $\$ 11$ and $\$ 14$ per hour, depending on seniority, along 
with sales incentives that typically scale closely with purchase price and average approximately \$4. Interestingly, however, sales incentives are only slightly higher for the 6-year warranty Energy Star models compared to their closest non-Energy Star substitutes, despite purchase prices that are about $\$ 200$ higher. Sales incentives for the premium 12-year warranty Energy Star models are about $\$ 5$ larger than for the standard 12-year warranty non-Energy Star models.

The Retailer has an established set of processes that sales agents are to follow on each call. About 60 to 65 percent of calls are recorded at random, and managers monitor a subset of these calls for evaluation and quality assurance. The sales agents meet with their managers weekly to review performance and talk about sales initiatives and modifications to the sales process.

When a customer calls, he or she is routed to the first available sales agent. The call centers use caller ID, and the agents verbally confirm the caller's phone number. Using this phone number, the customer is assigned a "reference number." We define a "consumer" as a unique reference number. Individuals often call more than once as they comparison shop or gather more information. If an individual calls more than once from the same phone number or verbally gives the same number to a sales agent, then he or she is tracked as a unique customer.

Once the sales agent and consumer agree on a water heater model, the sales agent checks whether the model is in stock in the customer's region, arrives at a price quote, records the customer address, and charges the customer's credit card. Customers can install the unit themselves, hire a third-party plumbing contractor, or pay the Retailer to do the installation.

\subsection{Experimental Design}

The sales agents have a standard computer interface that has the Retailer's sales program plus internet access. To implement the experiment, the Retailer's staff redesigned the interface to open the experiment website each time a reference number is entered. Our research team designed and programmed the experiment website, which afforded us full control over the randomization and other content.

Appendix Figure A.1 is a screen shot of the website's initial screen. On this screen, the agent would enter the customer's needed fuel type (Gas or Electric) and click "GO." After the agent clicked "GO," the website would display call handling instructions, including a script that the agent was to cover with the customer. The different treatments were implemented through these scripts. Appendix Figure A.2 is a screen shot of one example treatment, the $\$ 100$ Energy Star rebate. Electric customers are excluded from the experimental population, with the website displaying "No Script." Natural Gas customers form the experimental population, and they are randomly assigned to one of the treatment groups.

Agents and callers were both randomized. Agents were randomly assigned as Information Treatment Agents or Information Control Agents. Callers were randomly assigned to treatment groups based on their reference number. Thus, consumer who called multiple times but kept the 
same reference number remained in the same treatment condition. Consumers who first spoke with an Information Control Agent were automatically assigned to Information Control, while callers who first spoke with an Information Treatment Agent were randomly assigned to either Information Treatment or Information Control.

Table 2 displays the experimental timeline and treatment groups. Phase 1 ran from November 2012 to April 2013. During this time, there was a three-by-two matrix of treatments: customers were randomly assigned to $\$ 0, \$ 25$, or $\$ 100$ rebate, which was crossed with Information Treatment or Control. Phase 2 of the experiment ran from early April to early June 2013. In this phase, we added a sales incentive, which the Retailer calls a "spiff." Phase 3 lasted from early June to early July. In this phase, we added two final treatments, which were interactions of the spiff with the two rebate levels. In Phase 4, the Retailer ended the spiff treatments but continued the rest of the experiment for several weeks. In total, there were eight different treatment cells, plus control.

Below, we give examples of the call handling instructions for several example treatments. In the Information Treatment condition with no rebate, the website instructed the agent to read the following script to the customer:

Let me take a moment to tell you about our Energy Star models. Energy Star water heaters cost about \$220 more than a standard model, but they save a typical household $\$ 40$ each year, so you would make up that price difference in about six years. Over 12 years, which is the normal life of a water heater, you would save $\$ 480$ in energy bills. Energy Star models may not be available for every home. If possible, would an Energy Star water heater be of interest to you?

In the rebate condition with no information, the agent was instructed to say:

I have good news. [Retailer] has specially selected you for a $\$ 100$ rebate on any Energy Star water heater. Energy Star models may not be available for every home. If possible, would an Energy Star water heater be of interest to you?

If the customer was assigned to the spiff, the call handling instructions read:

ENERGY STAR SPIFF CALL

You (the Retail Hotline Associate) will receive \$25 on your next paycheck if this caller buys any Energy Star water heater. You can share with the caller any useful information about the benefits of Energy Star, perhaps including environmental benefits or long-run energy cost savings. The caller does not need to purchase on the initial call. If the same caller calls back later and uses the same reference number, all RHAs that spoke with that reference number earn the \$25.

In the combined spiff plus rebate conditions which were added in Phase 3, the sales agent was not instructed to read a specific script. Instead, the call handling instructions told sales agents that 
the customer was eligible for a rebate and left it to the sales agent to decide how to phrase that information.

\section{ENERGY STAR SPIFF CALL + \$25 CUSTOMER REBATE}

You (the Retail Hotline Associate) will receive $\$ 25$ on your next paycheck if this caller buys any Energy Star water heater.

The customer will also receive a \$25 rebate off of any qualifying Energy Star model.

In the control group, the instructions read:

CONTROL GROUP: NO SCRIPT

This customer is in the control group. Proceed with the call as you normally would. Answer any questions the customer has, but try not to use any of the language in the information treatment script.

At the end of the call, the sales agents reported in the experiment website whether or not they delivered the script. As we shall see, these self-reports overstate compliance relative to our independent audits. The website and the team managers instructed the agents that the only reasons not to deliver the script were if the customer needed a low-NOx, short tank, or other specialty model that was not substitutable with Energy Star models. If the agent did not complete the script, the website required them to select the reason for non-compliance from a dropdown menu.

The experiment was closely integrated into the call center processes. At the outset, managers trained the agents on the scripts and how to use the website, and this was also part of training for newly-hired agents during the experiment. We also communicated directly with the agents through several group emails and two videos that explained the importance of compliance with the experiment. Specifically, we emphasized the importance of both delivering the scripts on treatment group calls and not discussing elements of the scripts on control group calls.

Every week of the experiment, we provided the Retailer with agent-specific compliance reports based on self-reported compliance from the website. We had bi-weekly calls with managers to discuss these compliance reports, and managers could then discuss with agents in their weekly meetings. The Retailer's internal call monitors also audited calls for compliance with treatment assignment. Agents with low compliance with the experiment were pressured by managers to do better. To encourage competition between the two call centers, managers also reviewed average compliance for each call center, as well as trends over time. In the endline survey, sales agents reported that managers frequently emailed and talked with them about the experiment. In sum, agents did face some costs if they did not at least report compliance with the experimental protocols. However, this experiment was only one of many issues that managers and agents needed to attend to. 
Individuals who call multiple times from multiple phones and do not tell the sales agents that they have previously called would have been assigned different reference numbers, and thus potentially different treatments. This could generate spillovers, for example if a caller who purchases using an Information Control reference number had been assigned an Information Treatment reference number on a previous call. Based on our conversations with Retailer staff, we do not believe that this happens on more than a handful of calls, although we do not have a precise estimate.

Some consumers, perhaps plumbing contractors or landlords of multiple homes, order multiple water heaters during the experiment. The Retailer gives these individuals separate reference numbers on their separate purchases, and they are thus treated as separate "consumers" in the experiment. While this also could generate spillovers, it could not have more than a negligible impact on the estimates because it affects only a very small share of the sample: there are 104 individuals, or 0.4 percent of the sample, who order two water heaters from the same phone number, and no phone number appears more than twice in the sales data. $4^{4}$

\subsection{Data}

There are several main data sources. The first is the Retailer's call database. An observation consists of the unique customer reference number, date and time of the call, and the agent receiving the call. This database includes only sales calls, not warranty service, repairs, or other types of calls 5 Using the reference number, this is matched to the Retailer's purchase data, which include the model purchased, price paid, and other details.

The Retailer's call database is also matched by reference number to the experiment website database. This database includes the treatment assignment and the agent's self-reported compliance, for each reference number where the website was opened. For the 1.3 percent of reference numbers that appear in the website data multiple times, we code that the script was read to the consumer if any agent reported that he or she had done so on any call. In the regressions, each consumer $i$ must be associated with an individual agent $a$; we use the last agent in the website who spoke with customer $i]^{6}$ We define a variable $N_{\text {iat }}^{s}$ that takes value 1 if agent $a$ reported compliance on a treatment group call with consumer $i$, and 0 otherwise. Agents were not explicitly asked

\footnotetext{
${ }^{4}$ Other than perhaps these 104 individuals, the consumers that call the call center are the final owners of the water heater; contractors do not order through the retail hotline. Furthermore, consumers typically are not already working with a contractor before calling the Retailer, because a contractor would typically procure the water heater on behalf of a consumer.

${ }^{5}$ Approximately 2-3 percent of reference numbers are repeated, typically as the sales agent updates information. In these cases, we use the most recent observation. We drop six reference numbers that appear to be used twice for two distinct individuals.

${ }^{6}$ There are other ways to code this, but it would not matter, because almost all of the 1.3 percent of reference numbers that appear multiple times were entered by the same agent. Only four reference numbers were entered by two separate agents in the website, and none are entered by 3 or more. Because treatment groups were assigned by reference number, a consumer's treatment assignment is maintained even if an agent enters the same reference number multiple times.
} 
to read a script on spiff treatment calls or on controls calls. We define $N_{\text {iat }}^{s}$ as missing for spiff treatment calls and zero for control calls.

The total number of consumers (reference numbers for consumers interested in natural gas water heaters) recorded in the call database during the experiment is 38,179 . Of these, 23,347 (61 percent) are in the website and are randomly assigned to a treatment group; these calls comprise our "experimental population." The calls that are not recorded in the website are largely conversations that did not last long enough for the sales agent to activate the website. As Table 2 shows, 35 percent of consumers (8275 in total) purchased from the Retailer. Of these sales, 73 percent were either Energy Star models or were substitutable with Energy Star models given other attributes such as tank height and NOx emissions. Of this substitutable group, however, only 3.5 percent were actually Energy Star, while the remaining 96.5 percent were standard models.

For consumers that purchased water heaters, the Retailer records their name and address. Zip codes were used to match median income from the most recent American Community Survey (ACS) 5 -year estimates and the the share of vehicles registered in the zip code that are hybrids, which could be an important correlate of environmentalism and interest in energy efficiency. Using each purchaser's name and address, a marketing data company called Acxiom provided assessed home value, college graduate indicator, age, household size, and political affiliation. Acxiom gathers data from public records, magazine subscriptions, voting records, scanner data, online purchases, and other sources, and their data are certainly measured with error. For the approximately 10 percent of addresses missing the college graduate indicator, age, or household size, we substitute zip code-level means, again from the ACS 5-year estimates.

Using the Acxiom political affiliation data, we construct a variable called "Democrat" which takes value 1 if the purchaser is a registered democrat, 0 if a republican, and 0.5 if independent or unregistered. If political affiliation is missing, we replace Democrat with the county-level ratio of Democrat to Democrat plus Republican votes in the 2004 and 2008 presidential elections, using data from the U.S. Election Atlas (Leip 2013). Acxiom also provided two additional levels of environmentalism. "Environmentalist" is an indicator variable for whether the consumer subscribes to environmental magazines or contributes to environmental or animal welfare charities. "Green Living" is an indicator that takes value one if Environmentalist equals one or if the household purchases environmentally-healthy products such as eco-friendly soaps and organic foods.

Table 3 presents sample means and standard deviations for our nine demographic variables. Consumers in our sample are older and wealthier than the general population, likely related to the fact that they are almost entirely homeowners. They are also more liberal and environmentalist, as illustrated by their Democrat scores and zip code hybrid vehicle shares. In our data, Energy Star demand is positively associated with zip code median income, home value, and zip code hybrid share, reminiscent of the findings of Kahn (2007). This suggests that the Energy Star market share would be even lower in a nationally-representative sample. 
We do not have much information with which to test for balance on observables within the entire experimental population. Using the address-based demographic information, however, we can test for balance within the subset of consumers who purchased from the retailer. Appendix Table A.1 presents tests using the nine demographic variables for each of the eight treatment cells, relative to control. Only one of the 72 t-tests rejects equality with greater than 90 percent confidence, and all nine F-tests fail to reject that the treatment groups are balanced on observables.

\subsubsection{Customer Follow-Up Surveys}

We hired an independent call center to conduct telephone follow-up surveys of customers who had called between December 10 and June 29. We designed two separate surveys, one for consumers who had purchased from the Retailer and one for consumers who had called but not purchased. For purchasers, we asked a battery of questions covering household information, the water heater purchase process, and the Energy Star product. For non-purchasers, we asked whether they had purchased an Energy Star water heater and why they had decided not to buy from the Retailer. For this analysis, we focus on questions related to consumers' knowledge of the Energy Star model, which we only asked of purchasers. Any other results are certainly available upon request, and the survey protocols are available as part of the replication files.

We directed the call center to complete no more than 200 surveys of purchasers and as many surveys as possible of purchasers. In order to maximize response rates, we offered a $\$ 25$ gift card from the Retailer to any respondents who initially attempted to refuse; 149 people accepted. In total, there were 1,091 completed surveys (including 891 from purchasers) from 6,342 attempts, for a response rate of 17 percent.

\subsubsection{Independent Audits of Recorded Phone Calls}

Our research assistant (RA) audited 2,122 calls from natural gas water heater consumers recorded between May 1 and July 18. These 2,122 calls are all recorded calls assigned to any of the treatment groups during that period, along with approximately five calls per day from the control group. The audits were blind, meaning that the RA did not know the treatment assignment when auditing a call.

There are two reasons why a call is not observed in our audit data. First, the Retailer's software records only a randomly-selected 60 to 65 percent of calls. Second, the database of recorded calls is not organized by reference number, so our RA needed to match recordings to reference numbers using phone number, time and duration of call, and other information; not all calls could be matched.

We worked with the RA to develop a protocol for quantifying the content of the interaction 
between the sales agent and the customer.7 We measure the information provision process using six variables:

- Mentioned E-Star: Did the agent mention energy efficiency, energy use, or Energy Star?

- Rebate: Did the agent mention the experiment's Energy Star rebate from [the Retailer]?

- Saves Money: Did the agent mention that an Energy Star (or energy efficient) water heater saves money in energy costs?

- Payback Period: Did the agent quote a payback period?

- Read Script: Does the agent say one of the experiment scripts, either exactly or approximately?

- $\ln (E-S t a r$ Seconds): For how many seconds did the agent and the customer talk about energy efficiency, energy use, or Energy Star? We use the natural log of one plus this number.

Because there are a small share of consumers who call multiple times, the audit dataset includes multiple observations of some consumers. Thus, there are 2,069 unique consumers in our experimental population for whom we have audit data. For the five binary variables above, we collapse using the maximum. In other words, consistent with our construction of agents' self-reported compliance $N_{\text {iat }}^{s}$, we measure whether a consumer was ever informed about Energy Star or a rebate. For the sixth variable, the number of seconds discussing Energy Star, we take the sum across all of a consumer's calls.

\section{Model}

We present a simple model of information disclosure through agents in an imperfectly competitive market. The model is related to other models of informative and persuasive advertising, such as Becker and Murphy (1993), Dixit and Norman (1978), Dorfman and Steiner (1954), Kotowitz and Mathewson (1979), and Shapiro (1980). It builds most closely on the simple spatial competition model of Hotelling (1929) and the Grossman and Shapiro (1984) extension to informative advertising. We extend these models by modeling two goods, a base good and a high-quality good, and by nesting sales agents within the model, which provides microfoundations for the experiment's information disclosure process.

The model by itself would not be an important contribution, and what we call "propositions" are straightforward comparative statics. We include the model, however, because it helps to put the empirical work in context. The sales agent model generates predictions for the field experiment,

\footnotetext{
${ }^{7}$ By necessity, this was done before writing the paper, as the Retailer deletes call recordings after 30 days.
} 
under the realistic assumption that competing firms do not respond to our randomly-assigned treatments. We then solve for the two-firm equilibrium, which highlights potential policy implications.

\subsection{Setup}

\subsubsection{The Choice Set}

Two firms are located at either end of a Hotelling line. Aside from their locations, the firms are fully symmetric. Each firm sells two goods indexed by $j$ : a base good $I$ and a high-quality good $E$. For applications to energy-using durables such as water heaters, we have in mind that good $E$ is energy efficient and good $I$ is energy inefficient 8 The two goods are produced at marginal costs $c_{j}$, and firm $f$ sells good $j$ at price $p_{f j}$. Consumers have unit demand, meaning that they will buy one of the two goods from one of the two firms. The unit demand assumption is certainly appropriate for water heaters. The basic Hotelling setup also fits the water heater market very well, with horizontally-differentiated retailers selling closely-comparable sets of products.

\subsubsection{Consumers}

A group of consumers normalized to measure 1 is distributed uniformly along the Hotelling line, with locations indexed by $d \in[0,1]$. The variable $t$ measures "transport costs" - the utility of purchasing from the closer vs. more distant firm. Of course, $d$ could reflect brand loyalty or many factors other than geographic distance. There are two consumer types, High and Low, indexed $H$ and $L$, in proportions $\lambda$ and $1-\lambda$, respectively. Both types earn gross utility $V$ from owning the base good. A consumer at point $d$ realizes net utility $V-d t-p_{1 I}$ if purchasing good $I$ from firm 1 and $V-(1-d) t-p_{2 I}$ if purchasing from firm 2 .

When owning good $E$, low types earn gross utility $V_{L}$ and high types earn utility $V_{H}$, with $V_{H}>V_{L}$. In applications to energy-using durables, we have in mind that type $H$ has high utilization demand or other reason to prefer energy efficiency. A High type consumer at point $d$ realizes net utility $V_{H}-d t-p_{1 E}$ if purchasing good $E$ from firm 1 and $V_{H}-(1-d) t-p_{2 E}$ if purchasing from firm 2. Net utility for Low type consumers purchasing good $E$ is analogous, except with $V_{L}$ instead of $V_{H}$.

Define $G_{H E}=V_{H}-c_{E}$ and $G_{L E}=V_{L}-c_{E}$ as the surplus from allocating good $E$ to type $H$ and type $L$, respectively, and define $G_{I}=V-c_{I}$ as the surplus from allocating good $I$ to either type. We assume that $G_{H E}>G_{I}$ and $G_{L E}<G_{I}$, meaning that it is socially optimal to for High type consumers to purchase good $E$ and for Low type consumers to purchase good $I$.

Consumers are initially unaware that the high-quality good exists, and they become aware only if informed by a sales agent. Sales agents at firm $f$ inform consumers only about good $E$ sold by

\footnotetext{
${ }^{8}$ An energy efficient good may or may not be "high-quality" on other dimensions, but it is vertically differentiated in the literal sense that all consumers should prefer lower energy costs.
} 
firm $f$. For example, if a consumer is informed by an agent of firm 1, then he or she is aware only that firm 1 sells good $E$. Consumers informed by both firms are aware that both firms sell good $E$. There are thus four different types of consumers. Shares $\theta_{1}\left(1-\theta_{2}\right)$ and $\theta_{2}\left(1-\theta_{1}\right)$ are informed only by firm 1 or firm 2 , respectively. Share $\theta_{1} \theta_{2}$ is informed by both firms, while share $\left(1-\theta_{1}\right)\left(1-\theta_{2}\right)$ is informed by neither. We focus on the set of parameter values under which equilibrium prices are such that Low type consumers always purchase good $I$ and High type consumers purchase good $E$ if and only if they are informed.

Define $q_{f j}$ as the quantity of consumers that purchase good $j$ from firm $f$. Denote $d_{E}=$ $d_{E}\left(p_{1 E}, p_{2 E}, t\right)$ and $d_{I}=d_{I}\left(p_{1 I}, p_{2 I}, t\right)$ as the largest $d$ such that the consumer at that location purchases good $E$ and $I$, respectively, from firm 1. Consumers to the "left" of $d_{E}$ and $d_{I}$ (on a horizontal Hotelling line) purchase from firm 1, while consumers to the "right" purchase from firm 2 .

Low types and uninformed High types purchase good $I$, and they represent share $\left(1-\lambda\left(\theta_{1}+\right.\right.$ $\left.\left.\theta_{2}-\theta_{1} \theta_{2}\right)\right)$ of the population. Firm 1's quantity sold of good $I$ is thus $q_{1 I}\left(p_{1 I}, \theta_{1}\right)=d_{I}\left(1-\lambda\left(\theta_{1}+\right.\right.$ $\left.\left.\theta_{2}-\theta_{1} \theta_{2}\right)\right)$. Informed High types purchase good $E$. Share $\theta_{1}\left(1-\theta_{2}\right)$ have only been informed by firm 1 , and they thus purchase good $E$ from firm 1 with certainty. Share $\theta_{1} \theta_{2}$ have been informed by both firms, and such consumers purchase from firm 1 if they are located to the left of $d_{E}$. Thus, firm 1's quantity sold of good $E$ is $q_{1 E}\left(p_{1 E}, \theta_{1}\right)=\theta_{1}\left(1-\theta_{2}\right)+\theta_{1} \theta_{2} d_{E}$. Quantity equations for firm 2 are symmetric, except replacing $d_{I}$ and $d_{E}$ with $1-d_{I}$ and $1-d_{E}$, respectively.

\subsubsection{Sales Agents and Information Provision}

The firm employs a number of sales agents normalized to measure 1. As described above, providing information takes time and effort, and it reduces sales agents' ability to successfully carry out other required tasks during sales interactions. We assume that informing share $\theta_{f}$ of consumers costs firm $f$ 's sales agents $\frac{\alpha}{2} \theta_{f}^{2}$, where $\alpha$ is a scaling parameter. In the context of our field experiment, such costs to sales agents are necessary to explain why they sometimes do not deliver information when the experiment protocol directs them to. Convex costs are needed to generate a unique equilibrium, but this convexity also informally captures another important feature of our empirical results: as we shall see, sales agents are able to target their attempts at information provision at consumers who appear to be more receptive. This suggests that as sales agents attempt to inform more consumers, the marginal consumers are increasingly unreceptive.

The firm does not observe all individual sales interactions, so the firm cannot directly set $\theta_{f}$. Instead, firms pay sales agents a fixed wage $w_{f}$ plus sales incentive $s_{f}$ for each sale of good $E$. Sales agents are risk-neutral, and they maximize the following utility function:

$$
U\left(\theta_{f}\right)=s_{f} q_{f E}\left(p_{f E}, \theta_{f}\right)-\frac{\alpha}{2} \theta_{f}^{2}+w_{f}
$$


Agents have an outside option which gives utility $\bar{U}$, which gives the participation constraint that $U\left(\theta_{f}\right) \geq \bar{U}$.

\subsection{Sales Agent Information Provision Behavior}

Agents inform consumers until the marginal incentive pay equals the marginal cost of information provision. Plugging in for $q_{1 E}$ and maximizing agents' utility gives agents' utility-maximizing choice of information provision, which we denote as $\tilde{\theta}_{f}$. For firm 1, this is:

$$
\tilde{\theta}_{1}=\frac{s_{1}}{\alpha} \cdot \frac{\partial q_{1 E}\left(p_{1 E}, \tilde{\theta}_{1}\right)}{\partial \theta_{1}}=\frac{s_{1}}{\alpha} \lambda\left[\left(1-\theta_{2}\right)+\frac{p_{2 E}+t-p_{1 E}}{2 t} \theta_{2}\right]
$$

The equation for firm 2 is symmetric.

In our empirical work, we study how changes in price and sales incentives affect agents' information provision and consumers' purchases. Because the experimental treatment groups are a small share of the overall market, the results are likely to be informative about the best response functions for the Retailer and its sales agents, not equilibrium effects after competing firms re-optimize. The model generates three very simple comparative statics, which we label as Propositions 1-3.

Proposition 1 covers the initial sales agent behavior, independent of any experimental manipulations. It states that agents inform consumers more when potential demand from informed consumers is larger.

Proposition $1 \frac{\partial \tilde{\theta}_{f}}{\partial p_{f E}}<0$ and $\frac{\partial \tilde{\theta}_{f}}{\partial \lambda}>0$.

Proposition 1 follows immediately from Equation (2). Intuitively, the proposition states that agents do not bother to inform consumers if information doesn't increase demand. This could occur either if the price is high or if most consumers are Low types.

Proposition 2 covers agents' response to changes in the sales incentive.

Proposition $2 \frac{\partial \tilde{\theta}_{f}}{\partial s_{f}}>0$. Furthermore, $\frac{\partial^{2} \tilde{\theta}_{f}}{\partial s_{f} \partial p_{f E}}<0$ and $\frac{\partial^{2} \tilde{\theta}_{f}}{\partial s_{f} \partial \lambda}>0$.

The first part of Proposition 2 states the straightforward result that agents provide more information about good $E$ if incentivized to sell $\operatorname{good} E$. The second part states that if information doesn't increase demand very much, sales incentives do not induce agents to provide much more information. Put simply, agents are unresponsive to sales incentives if consumers don't respond to agents' actions. Both parts of this proposition follow from taking derivatives of Equation (2).

Our experiment varies both high-quality good price $p_{f E}$ and sales incentive $s_{f}$. Should these have independent effects on quantity demanded, or should a lower price reinforce the impacts of a larger sales incentive?

Proposition $3 \frac{\partial^{2} q_{f E}}{\partial p_{f E} \partial s_{f}}<0$. 
Proposition 3 states that the effects of lower prices and higher sales incentives reinforce each other. When prices are lower, the potential quantity demanded from High types is higher, making sales agents more responsive to increases in the sales incentive. When the sales incentive is higher, sales agent behavior is more responsive to changes in potential quantity demanded that result from lower prices. This follows from taking derivatives of $q_{f E}\left(p_{f E}, \tilde{\theta}_{f}\right)$; see Appendix A.

\subsection{Market Equilibrium}

\subsubsection{The Profit Function}

Firms set prices, sales incentives, and wages to maximize profits. The profit function for firm 1 is:

$$
\pi_{1}\left(p_{1 I}, p_{1 E}, s_{1}, w_{1}\right)=q_{1 I}\left(p_{1 I}, \tilde{\theta}_{1}\right)\left[p_{1 I}-c_{I}\right]+q_{1 E}\left(p_{1 E}, \tilde{\theta}_{1}\right)\left[p_{1 E}-c_{E}-s_{1}\right]-w_{1}
$$

Substituting the sales agents' participation constraint into the profit function (and dropping the tilde on $\theta$ for simplicity) gives:

$$
\pi_{1}\left(p_{1 I}, p_{1 E}, \theta_{1}\right)=q_{1 I}\left(p_{1 I}, \theta_{1}\right)\left[p_{1 I}-c_{I}\right]+q_{1 E}\left(p_{1 E}, \theta_{1}\right)\left[p_{1 E}-c_{E}\right]-\frac{\alpha}{2} \theta_{1}^{2}-\bar{U}
$$

The fact that Equation (3) reduces to Equation (4) implies that when setting the sales incentive, the firm acts as if it maximizes profits net of agents' information costs. Thus, although the firm does not explicitly contract on agents' information provision $\theta_{f}$, this does not generate inefficiency. Because both firm and agent are risk neutral and the agent does not have limited liability, the firm does not need to insure the agent, and the firm's choice of $s_{f}$ will maximize the sum of profits and agent utility. Thus, there is no "agency problem" of the traditional sort.

\subsubsection{Equilibrium}

Appendix A solves for the symmetric Nash equilibrium. As in the standard textbook model, equilibrium prices are $p_{f I}^{*}=c_{I}+t$ and $p_{f E}^{*}=c_{E}+\left(\frac{2}{\theta_{f}^{*}}-1\right) t$. Notice that unless $\theta_{f}^{*}=1$, $p_{f E}^{*}-c_{E}>p_{f I}^{*}-c_{I}$, as imperfect information about competitors' product availability gives firms additional market power when selling good $E$.

The equilibrium information provision level is $\theta_{f}^{*}=\frac{-5+\sqrt{32 \frac{\alpha}{\lambda t}-7}}{4\left(\frac{\alpha}{\lambda t}-1\right)}$. This is decreasing in information cost $\alpha$. It is increasing in the share of High types $\lambda$, as more High types increase the chance that an informed consumer will purchase good $E$, which has higher markup. Intuitively, if there are not many High types in the population, firms will not try hard to inform all consumers just to change decisions by the small number of consumers who might purchase good $E$. Information provision is also increasing in $t$, because higher transport cost increases the relative markup on good $E$, which increases the returns to informing consumers about that good. 


\subsection{Social Welfare}

Social welfare can be written as surplus from High types plus surplus from Low types net of information provision costs and transport costs. In the symmetric equilibrium where Low type consumers always purchase good $I$ and High type consumers may purchase either good depending on $\theta_{f}$, social welfare can be written as:

$$
S W\left(\theta_{f}\right)=\lambda\left[\left(2 \theta_{f}-\theta_{f}^{2}\right) G_{H E}+\left(1-\theta_{f}\right)^{2} G_{I}\right]+(1-\lambda) G_{I}-\alpha \theta_{f}^{2}-\frac{t}{4}
$$

Because consumers have unit demand, there is no extensive margin distortion from oligopoly pricing: although the market is not perfectly competitive, prices do not distort total quantity demanded. Furthermore, because firms are symmetric, they offer the same price in equilibrium, and there is no way to reduce the losses from transport costs. Therefore, distortions arise only when consumers purchase a good which is not optimal given their type - in particular, when High types do not purchase good $E$ because they are uninformed.

Appendix A derives the socially-optimal level of information provision $\theta^{+}$and shows that it could be greater than, less than, or equal to the market equilibrium level. The market is more likely to under-provide information when the social gain $G_{H E}-G_{I}$ from moving consumers to good $E$ is large or when market power $t$ is small.

We assume that the government cannot directly mandate sales agents or firms to achieve $\theta^{+}$, which seems realistic in most contexts. Instead, consider a government that has two potential policy instruments: a minimum quality standard or a sales incentive for good $E$ provided directly to the agent $\square^{9}$ What are the welfare implications?

\subsubsection{Welfare Effects of a Minimum Quality Standard}

As discussed in the introduction, minimum energy efficiency standards are often justified by the assertion that imperfect information reduces demand for energy efficient goods. In this model, one can capture the effects of a minimum quality standard by eliminating the base good and requiring that all consumers purchase good $E$. Under our assumptions about $G_{H E}, G_{L E}$, and $G_{I}$, this increases welfare for High type consumers but decreases welfare for Low types. A minimum quality standard also eliminates information provision costs, as all consumers now are mandated to purchase good $E$. Under a minimum quality standard, social welfare is:

\footnotetext{
${ }^{9}$ Our model is not well-suited to consider a subsidy for good $E$. In our model, a subsidy for good $E$ is equivalent to an equal reduction in marginal cost for both firms. As long as the subsidized price still exceeds $p_{f I}^{*}$, firms pass the subsidy on to consumers in the form of reduced prices, but because the price reduction is symmetric, there is no change in $\theta^{*}$. Thus, no additional consumers are informed, and the market equilibrium is unaffected except for the transfer from taxpayers to the government to firms to some High types. This result would be different if we had a continuum of quality preferences instead of just binary $H$ and $L$ types. Note that in Propositions 1 and 3 and in our experiment, only one firm reduces prices, so $\tilde{\theta}_{f}$ and $q_{f E}$ do respond to changes in $p_{f E}$.
} 


$$
S W^{\text {standard }}=\lambda G_{H E}+(1-\lambda) G_{L E}-\frac{t}{4}
$$

Subtracting the $S W\left(\theta_{f}^{*}\right)$ as written in Equation (5), we have the welfare gains of a standard relative to the market equilibrium:

$$
S W^{\text {standard }}-S W\left(\theta_{f}^{*}\right)=\lambda\left(1-\theta_{f}^{*}\right)^{2}\left(G_{H E}-G_{I}\right)+(1-\lambda)\left(G_{L E}-G_{I}\right)+\alpha \theta_{f}^{* 2}
$$

The first term is gains to the share of High types that are uninformed in the market equilibrium. The second term is negative, capturing losses from Low types who must now purchase good $E$. The third term is savings in information provision costs. Welfare gains are mechanically larger when the social gains from good $E$ are larger and when there are more High types. Welfare gains are also larger when $\alpha$ is large, i.e. when it is costly to inform consumers.

\subsubsection{Welfare Effects of Government-Provided Sales Incentives}

Unlike minimum quality standards, it would be novel for governments to provide sales incentives directly to sales agents. What effects would this have in this model? Consider the case where firms under-provide information relative to the social optimum (i.e. $\theta^{+}>\theta^{*}$ ), so the government would like to subsidize information provision. Assume that the government can fund the subsidy with lump-sum taxes.

If firms can set $s<0$ (or provide a higher sales incentive for good $I$ ), then government-provided sales incentives act just like a marginal cost reduction, and firms will offset the government incentive to arrive at their profit maximizing level of information provision in Equation (18). However, consider the potentially-realistic case where the firm cannot set $s<0$, i.e. it cannot pay its agents to not sell a product or otherwise undo the government-provided sales incentive. In this case, the government will set the sales incentive that induces the socially-optimal information provision effort, and the firm will provide no additional sales incentive and will adjust the fixed wage such that agents' participation constraint binds. Substituting $\theta^{+}$into the agents' first-order condition in Equation (2) and simplifying, this gives the socially-optimal government-provided sales incentive:

$$
s^{+}=\frac{\alpha \theta^{+}}{\lambda\left(1-\frac{1}{2} \theta^{+}\right)}
$$

Increased information provision also has the side effect of increasing competition in the market for good $E$, so both firms decrease their prices $p_{f E}^{*}$. In this model, this has no welfare implications, but it does generate a transfer from firms to consumers. 


\subsection{Discussion}

The model helps to understand and motivate the field experiment that we detail in the remainder of the paper. The three simple propositions show that sales agent behavior is not only important in directly determining the firm's ability to disclose information, but also indirectly informative about consumers' preferences: because information provision is costly, optimizing agents will not inform consumers if they believe that information will not affect demand. The social welfare discussion highlights that if sellers' information disclosure is not effective at increasing demand for high quality goods but the social benefit of allocating good $E$ to High types $\left(G_{H E}-G_{I}\right)$ is large, minimum quality (energy efficiency) standards are more likely to increase welfare. Before drawing this conclusion, however, we would need to show that information provision is ineffective because disclosure is difficult (i.e. $\alpha$ is large), not because consumers still don't want good $E$ after being informed (i.e. $\lambda$ is small). The model also highlights a novel policy that could increase welfare: government-provided sales incentives. To evaluate this potential policy, one similarly needs to know $\alpha$ and $\lambda$, along with $\left(G_{H E}-G_{I}\right)$.

\section{$5 \quad$ Experiment Results}

\subsection{Sales Agent Behavior}

Define $N_{\text {iat }}$ as a measure of whether agent $a$ provides information to consumer $i$ during phase $t$ of the experiment. We observe sales agent behavior from two sources: self-reported compliance $N_{\text {iat }}^{s}$ and the independent audits. While the latter measure is only available for a smaller subset of calls, it is an independent assessment and also provides multiple measures of what the sales agent said. $\mathbf{T}_{i}$ is a vector of indicator variables for each of the eight treatment cells. We estimate how $N_{i a t}$ varies across treatments using the following equation, where $\phi_{t}$ is a vector of indicators for the four phases of the experiment, $\mu_{a}$ is an agent fixed effect, and $v_{i a t}$ is the error term:

$$
N_{i a t}=\beta \mathbf{T}_{i}+\phi_{t}+\mu_{a}+v_{i a t}
$$

The $\phi_{t}$ and $\mu_{a}$ controls are necessary because assignment probabilities vary across phases as we added treatment groups and across agents who were assigned to Information Treatment or Control. This equation is estimated as a linear probability model (LPM) in OLS with robust standard errors. In typical cases like ours where the true probability model is not known, Angrist and Pischke (2012) advocate for using the LPM instead of an arbitrary non-linear model such as probit or logit, and we follow their recommendation. In practice, our results are qualitatively and quantitatively very similar when using probit, logit, or the LPM.

Column 1 of Table 4 presents the results using self-reported compliance $N_{\text {iat }}^{s}$ as the measure of compliance. The sample excludes the spiff treatment calls because agents were not explicitly 
asked to read a script on these calls. Agents report that they read the script on 46 to 49 percent of calls, and this depends little on treatment assignment. Columns 2-7 use data from our independent audits, showing that self-reports substantially overstate compliance. Relative to control group calls, agents were about ten percent more likely to mention Energy Star in Information Only treatment group calls, and about 14 percent more likely to do so in Rebate Only calls.

Columns 3-6 directly measure compliance with the experiment scripts. Column 3 shows that agents mentioned the experiment's Energy Star rebate on 14 to 24 percent of calls when the website directed them to. Columns 4 and 5 show that agents disclosed elements of the information script (quoted a payback period and/or said that Energy Star saves money) on 9 to 17 percent more information treatment calls relative to control.

Column 6 reports whether an agent said something approximating one of the treatment scripts during the call. These results are consistent with the results in columns 3 , 4, and 5 , in that agents appear to comply with the experiment protocol on about 15 to 20 percent of calls. The number of observations is lower in this column because we did not begin to record this variable until after the first 326 audits were completed. The outcome variable in column 7 is the natural log of one plus the estimated number of seconds that the agent and customer discussed energy efficiency; it is 33 to 62 log points larger in the information and rebate treatment groups.

The bottom row of Table 4 gives the mean of each dependent variable in the control group. Agent-reported compliance in column 1 is zero by definition in the control group because the website did not ask agents to report whether they complied on control group calls. Although agents do mention Energy Star on some control group calls, they almost never deliver a script erroneously to the control group: out of the more than 400 control group calls that were audited, agents quoted a payback period once and mentioned an Energy Star rebate twice. In total, they gave information that sounded like one of the treatment scripts to the control group less than one percent of the time. Column 3 shows that agents did mention a rebate on a small but statistically significant share of non-rebate treatment group calls - both Information Only and Spiff Only calls. This may reflect some small amount of recording error in the audits or mistakes by the sales agents.

\subsubsection{Measuring Sales Agent Compliance}

For use in the next section, we use the audit data to construct a measure of compliance with the experiment scripts. This variable is intended to measure explicit compliance with the experiment scripts, not any other form of discussion of energy efficiency. For consumers whose calls were audited, we define an indicator variable $N_{i a t}^{+}$that takes value 1 if an agent read a script on any treatment group call, mentioned an Energy Star rebate on a rebate call, or quoted a payback period on an information call. $N_{i a t}^{+}$takes value zero otherwise.

There is substantial variation in compliance across agents. Define $\bar{N}_{a}^{+}$as the mean of $N_{i a t}^{+}$across all of agent $a$ 's calls, excluding the Spiff Only and control calls. Figure 1 shows the CDF of $\bar{N}_{a}^{+}$ 
for all agents who were audited more than five times. About one-quarter of agents never comply, the median $\bar{N}_{a}^{+}$is 11 percent, and one quarter of agents comply more than 40 percent of the time. This dispersion implies that we can exploit variation in compliance rates across agents to improve power in tests of the effects of information provision on demand. Using the data in this graph, we group agents into four compliance groups with $\bar{N}_{a}^{+}=0,0<\bar{N}_{a}^{+} \leq 0.2,0.2<\bar{N}_{a}^{+} \leq 0.4$, and $\bar{N}_{a}^{+} \geq 0.4$. We define $G_{a}$ as the mean of $\bar{N}_{a}^{+}$across all agents within agent $a$ 's compliance group, where agent $a$ is the agent with whom consumer $i$ had his or her final call. The mean values of $G_{a}$ for agents in the four compliance groups are 0, 0.08, 0.29, and 0.53 respectively. Agents who were audited fewer than five times are automatically assigned the $G_{a}$ for the second compliance group, which includes the median $\bar{N}_{a}^{+}$.

\subsubsection{Spillovers of Information Provision to Non-Information Group Calls}

One reason why agents might not provide much information about Energy Star is that they might not know what to say, or might not be well-practiced in discussing energy efficiency. To test whether agents learn to disclose information, we exploit the fact that the experiment induced Information Treatment Agents to repeatedly deliver the Energy Star informational script, while Information Control Agents were never directly exposed. We regress the same compliance measures from Table 4 on the interaction of Information Treatment Agent indicator variables with a vector of treatment group indicators. Defining $I_{a}$ as an indicator variable for whether agent $a$ is assigned as an Information Treatment Agent, the regression is:

$$
N_{i a t}=\gamma \mathbf{T}_{i} I_{a}+\beta \mathbf{T}_{i}+\phi_{t}+v_{i a t}
$$

Standard errors are clustered by agent. Table 5 presents the estimated $\gamma$ coefficients on the interactions of $I_{a}$ with call treatment assignment indicators $\mathbf{T}_{i}$. The table parallels Table 4, with three exceptions. First, to increase power, we combine the $\$ 25$ and $\$ 100$ Rebate groups into one indicator. Second, the samples exclude information treatment calls, because Information Control Agents do not have any information treatment calls, and the objective is to compare information provision on non-information group calls. Third, we do not present regressions for Payback Period, because agents only quoted payback periods on four audited non-information group calls. (All four involved Information Treatment Agents.)

Table 5 shows that Information Treatment Agents are not more likely than Information Control Agents to mention experimental rebates on calls in any treatment group. Information Treatment Agents are, however, more likely to mention Energy Star on control calls and to mention that Energy Star saves money on Spiff Only calls. Column 6 shows that Information Treatment Agents talk about Energy Star for approximately 30 percent longer on Spiff Only and control group calls. The standard errors are too wide to determine whether there is a meaningful difference in information 
provision on combination Spiff plus Rebate calls.

These results have two implications. First, they suggest that one reason why the Retailer's sales agents do not frequently discuss information is that they were not well-practiced at doing so. Once Information Treatment Agents learned how to discuss Energy Star on information treatment calls, they began to do so without explicit instruction on control and spiff calls. In the context of our model, the experiment reduced the cost of information provision $\alpha$ for Information Treatment Agents. Second, these results imply that the estimates of effects of information disclosure on sales should take account of spillovers, in the form of increased discussion of energy efficiency on control group calls.

\subsection{Effects on Consumer Choice}

We examine two binary outcomes $Y_{\text {iat }}$ : whether the consumer purchases any model from the Retailer and whether the consumer purchases an Energy Star model. For each outcome, we run three specifications. The first specification is the intent-to-treat (ITT) estimator:

$$
Y_{\text {iat }}=\tau \mathbf{T}_{i}+\phi_{i}+\mu_{a}+\varepsilon_{i a t}
$$

As above, this includes agent and phase indicator variables 10

The second specification is an instrumental variables (IV) estimator, substituting agent-reported compliance $N_{\text {iat }}^{s}$ for $\mathbf{T}_{i}$ in Equation (11) and instrumenting for $N_{\text {iat }}^{s}$ with $\mathbf{T}_{i}{ }^{11}$ This sample is smaller because it excludes the spiff treatment calls, as $N_{i a t}^{s}$ is undefined for these calls. The third specification is what we call the "Scaled ITT" estimate: we interact $\mathbf{T}_{i}$ with $G_{a}$, which reflects the probability that agent $a$ delivered the specific information or rebate script to consumer $i$. Intuitively, multiplying by compliance probability scales the $\tau$ coefficient to be equivalent to a Local Average Treatment Effect (LATE) ${ }^{12}$

In this context, the ITT and LATE are likely to bound the average treatment effect of providing information to all consumers. While the ATE could theoretically be larger than the LATE if sales agents targeted information at the least responsive consumers, we shall see momentarily that agents appear to target consumers who are more interested in Energy Star. If all treatment group consumers with $N_{i a t}=0$ would have had zero treatment effect, then the ITT equals the ATE. On the other hand, if the agents quasi-randomly chose whom to disclose to, then consumers with $N_{i a t}=0$ and $N_{i a t}=1$ would have the same treatment effect, and the LATE would equal the ATE.

\footnotetext{
${ }^{10}$ Once we control for phases, additional time controls do not improve consistency or efficiency. Adding month-ofsample indicators, for example, does not change coefficients or standard errors. Furthermore, the estimates do not change when we exclude Phase I, which pre-dated the introduction of the spiff.

${ }^{11}$ Our previous working paper contained an error in this sentence that incorrectly described our IV procedure.

${ }^{12} N_{i a t}^{+}$is not statistically different across phases or treatment groups, so we cannot increase precision by also projecting $\phi_{i}$ or $\mathbf{T}_{i}$ onto $G_{i a}$. Although $G_{i a}$ is a mean calculated with sampling error using the audit data, we calculate that adjusting for sampling error in this generated regressor has only a small impact on the standard errors.
} 
Table 6 presents the results. The left three columns show effects on overall sales of any model from the Retailer. The right three columns show effects on Energy Star sales. Within each set of three columns, the first is the ITT, the second is the IV using agent-reported compliance, and the third regression is the Scaled ITT. Because the interaction effects between information and the two rebate level are never statistically significant, we drop these terms and report results for six major treatment groups relative to control. At the bottom of the table, we report the mean purchase probabilities in the control group: about 36 percent of consumers purchase from the Retailer, and about 0.9 percent of consumers purchase an Energy Star model.

The treatments have no effect on overall sales, except that the ITT and self-report IV suggest that a $\$ 25$ rebate may reduce purchase probability. One explanation for this is that even mentioning a small rebate for a different model generates a version of choice overload, complicating the sales interaction and causing a slight decrease in purchase probability. This would be consistent with other evidence of choice overload, such as Iyengar and Lepper (2000). Another explanation is that the result is spurious and would not replicate. We find this latter explanation more plausible, partially because there is no negative effect in the Scaled ITT. Intuitively, the Scaled ITT differs from the ITT because it weights more heavily the treatment effects from more compliant agents. The fact that the negative association disappears in the Scaled ITT implies that the ITT effect is driven by agents who aren't actually doing anything to comply with the experiment, which suggests a spurious correlation. The first two columns of Appendix Table A.2 replicate column 1 for agents in the bottom two vs. top two compliance groups, confirming that none of the treatments affect sales in the subsample of more compliant agents.

Although there appears to be little or no effect on the Retailer's overall sales, columns 4-6 show that the treatments do shift the composition of sales toward Energy Star. The $\$ 100$ rebate increases Energy Star purchase probability by 0.006 to 0.037 percentage points in the three specifications ${ }^{13}$ This effect is large against a control group market share of 0.9 percent, although it is small as a share of the total potential market. The combination of a spiff and $\$ 100$ rebate has a very large point estimate, increasing purchase probability by 4 to 22 percentage points. The standard errors are wide, as this treatment was only offered to a small share of consumers in phase 3 of the experiment.

The information treatments have a tightly estimated zero statistical effect. In column 6 , the standard errors are tight enough to bound the Local Average Treatment Effect at less than 1.5 percentage points. While this would represent a large percent increase in Energy Star purchase probability given the small base, the effect in percentage point terms is economically small.

Earlier, we documented that although agents effectively never explicitly read a treatment script on a control call, Information Treatment Agents are more likely to mention Energy Star on control calls. If this increases the probability of Energy Star purchase, then the estimates in Table 6 would

\footnotetext{
${ }^{13}$ In column 4 , the combination of the spiff and a $\$ 25$ rebate appears to reduce demand for Energy Star. We suspect that this result also would not replicate, and it is not statistically significant in the Scaled ITT in column 6.
} 
understate the true effects of the information scripts. The audit data allow us to address such spillovers. We construct an alternative "Scaled ITT" estimator, interacting $\mathbf{T}_{i}$ with each compliance group's average difference in Mentioned E-Star between treatment and control calls. Intuitively, this scales the treatment effect to equal a LATE with Mentioned E-Star as the endogenous variable. The third column of Appendix Table A.2 presents the results. The coefficients and standard errors are inflated, as one should expect from the fact that the coefficients in Table 4 are smaller for Mentioned Energy Star than for the variables used to construct $G_{i a}$. The qualitative results are similar: the Spiff and $\$ 100$ Rebate combination still has a very large effect, and the standard errors bound the information effect at no more than 2.7 percent with 90 percent confidence.

As discussed in Section 2.3. Energy Star models are only substitutable with some standard models. Under the assumption that the treatments do not affect whether or not consumers purchase a substitutable model, we can consistently estimate treatment effects within the sample to the set of consumers that purchase substitutable models. Appendix Table A.3 presents results. The coefficients are larger than in Table 6, as one should expect from excluding consumers with smaller treatment effects ${ }^{14}$ The qualitative results are also similar: the Spiff and $\$ 100$ Rebate combination has a very large effect, and the standard errors bound the information effect at no more than 4.9 percentage points with 90 percent confidence in the "Scaled ITT." For comparison, Energy Star represents 3.4 percent of substitutable models. The standard errors suggest that even if sales agents provided information to all callers, Energy Star would still not represent more than $4.9+3.4=8.3$ percent of the market of substitutable models. Thus, the lack of seller-provided information does not explain much of the low takeup of energy efficient water heaters.

Appendix Table A.4 presents alternative estimates using a probit estimator; the signs and discrete significance levels are the same or stronger.

\subsection{Targeted Information Disclosure}

Table 4 documents that the sales agents only partially comply with the experiment. Are agents strategic in providing information to consumers that are more interested in energy efficiency? Recall that $N_{i a t}^{s}$ is an indicator for whether the consumer is in a treatment group and the agent reported compliance with delivering the script, and define $T_{i}$ as an indicator for whether consumer $i$ is in any rebate or informational treatment group. We exclude the spiff treatment calls because there was no script for the agent to "comply" with on these calls. Table 7 reports estimates of the following regression:

$$
Y_{i a t}=\xi T_{i} N_{i a t}^{s}+\kappa T_{i}\left(1-N_{i a t}^{s}\right)+\phi_{i}+\mu_{a}+\varepsilon_{i a t}
$$

\footnotetext{
${ }^{14}$ Energy Star model availability and consumer preferences vary by geography, so if geography were somehow imbalanced across treatment groups, our coefficient estimates would be biased. Appendix Table A.3 also shows that the coefficient estimates are very similar when also including indicators for each purchaser's three-digit zip code. Of course, this is to be expected in a randomized experiment.
} 
As outcome variables $Y_{i a t}$, we use two different measures of interest in energy efficiency, both of which could be affected by the treatments. To construct the dependent variable in column 1 , we exploit an open-answer question from the follow-up survey: What were the two most important factors in your water heater purchase decision? The dependent variable is an indicator taking value one for the consumers who had one of their two factors coded as "saving energy and/or environmental conservation." The dependent variable in columns 2-4 is an indicator for whether the consumer purchased Energy Star. These regressions use agent-reported compliance because the sample of audits is too small for sufficient power.

The coefficient $\kappa$ measures the difference in $Y_{\text {iat }}$ between treatment group consumers who did not receive the treatment and the control group, while $\xi$ measures the difference between treatment group consumers who did receive the treatment (according to the agents' self-reports) and the control. $\xi$ is a mix of selection effects and treatment effects, while $\kappa$ is purely selection effects. If $\kappa<0$, this implies that the consumers to whom agents are not disclosing information are less likely than average to purchase Energy Star, and thus that consumers who are provided with information are more likely than average to purchase Energy Star. While this is not the same as targeting information disclosure at consumers who will have the largest treatment effects, it implies targeting in a different and likely related sense.

In all four columns of Table 7, the statistically negative estimates of $\kappa$ shows that agents are more likely to report delivering the script to consumers that are more interested in energy efficiency. Column 3 includes in the sample only consumers who purchase substitutable models. Even within this group, agents still target consumers with a higher probability of purchasing Energy Star. Column 4 includes controls for the nine address-based demographic variables. Because these covariates are missing for consumers who did not purchase from the Retailer, the sample is limited to consumers who purchased from the Retailer. The fact that $\kappa$ is still negative after conditioning on observables shows that agents target information provision based on other unobservable factors.

How is such targeting possible? Based on conversations with sales agents and with our research assistant who carried out the audits, we believe that agents learn about the consumer's preferences as the call continues. Agents may have delayed reading the Energy Star script until later in the call, after having the chance to gauge the consumer's receptiveness.

\subsection{Relationship to the Model}

Our main empirical results tell a coherent story that is consistent with the three propositions in Section 4. Proposition 1 states that agents will not inform consumers if information does not increase demand. Results in Table 6 and related appendix tables show that information increases Energy Star sales by at most a few percentage points, even when focusing on the Scaled ITT estimates and limiting the sample only to consumers who are purchasing water heaters that are substitutable with Energy Star models. Consistent with this and with Proposition 1, the audit 
data show that agents spent very little time discussing Energy Star unless the experiment website directed them to. Agents mentioned Energy Star on only 13 percent of control group calls, and the median time spent discussing Energy Star within this 13 percent was 15 seconds.

Proposition 2 states that agents will provide more information when incentivized to do so, but they will not be very responsive to sales incentives if information has small effects on demand. The audit data show that agents provide at best slightly more information about Energy Star on no-rebate spiff calls compared to control: in Table 4, the coefficient on 1(Spiff Only) is positive but not statistically significant in columns $2,4,6$, and 7 .

Both of Propositions 1 and 2 illustrate the interaction between the supply and demand sides of the market. It was difficult for the Retailer to increase information provision through the experiment because their sales agents knew that most consumers would be unresponsive to the information. The small Local Average Treatment Effects in the IV and Scaled ITT estimators, combined with the targeting results in Table 7, suggest that agents' lack of compliance is best characterized as "strategic," not "shirking." In the context of the model, we mean that agents' information disclosure cost $\alpha$ is low enough that if more consumers were "High types" that would potentially be interested in Energy Star, agents might devote more effort to marketing those models.

Proposition 3 states that sales incentives and customer rebates reinforce each other, because the rebate increases sales agents' gains from responding to the sales incentive. Although the standard errors are wide, the point estimates in the sales data in Table 6 strongly support this: the combined Spiff and $\$ 100$ rebate treatment substantially increases Energy Star purchase probability. The audit data provide evidence that is suggestive of the microfoundations for this result. Specifically, agents appear to be slightly more likely to market Energy Star on the spiff treatment calls as the rebates increase from $\$ 0$ to $\$ 25$ to $\$ 100$ : in Table 6, the point estimates in columns 2, 3, 4, 6, and 7 all increase as the rebates increase.

Finally, the model considers a potential role for government-provided sales incentives, which could perhaps be a complement to product subsidies traditionally offered by governments and utility energy efficiency programs. The empirical results in Table 6 suggest a strong complementarity between price reductions and sales incentives. The model clarifies that government-provided incentives could increase welfare in the presence of an informational market failure, as long as firms are not able to fully "undo" the government incentive by changing their agents' compensation structure.

\subsection{Why Is Demand for Energy Star Low?}

Equation (7) shows that a minimum energy efficiency standard is more likely to increase welfare if the energy efficient product generates utility gains for a larger share of the population or if the cost of providing information is high. Our results show that the experimental attempts at information provision do not significantly increase Energy Star demand. Does this suggest that minimum energy 
efficiency standards might increase welfare by addressing imperfect information?

A first potential explanation for our empirical results is that although the Energy Star product would generate gains for many consumers, the Retailer is not able to credibly inform consumers of this, perhaps due to time constraints on the sales interactions or an inability to credibly convey attributes of this higher-priced product. If this were true, many consumers would remain unaware of Energy Star and unconvinced of the cost savings. A second explanation is that the Energy Star model would not in fact generate utility gains for many consumers, and consumers make an informed decision to not purchase the product. If this were true, consumers would be aware of the Energy Star product and the potential energy cost savings.

We use results from the follow-up surveys to measure the importance of these two explanations. Near the end of the survey, we asked consumers, Some water heater models that use less energy are officially designated as Energy Star. Did you buy an Energy Star model? The results suggest substantial confusion, consistent with the first explanation. The top panel of Table 8 shows that while only 2.1 percent actually purchased Energy Star, 52 percent of survey respondents think that they did. This should be interpreted cautiously, as there could have been experimenter demand effects: respondents may not have wanted to tell the interviewer that they had not purchased the Energy Star option. We designed the survey specifically to reduce demand effects: this was the first question we asked about energy efficiency, and we asked it after a series of other questions that signaled that the interviewer was not particularly interested in energy.

Respondents who said they had not purchased Energy Star, or who were "Not Sure" but in fact had not, were asked why they had not purchased Energy Star. The bottom panel of Table 8 shows that the primary reason was high prices. This is consistent with the second explanation of informed consumers choosing not to purchase Energy Star. Fifteen percent of these consumers (or about seven percent of the entire surveyed population) report being unaware that there was an Energy Star option.

The follow-up survey also elicited beliefs over energy costs for standard models and energy cost savings from Energy Star models. Table 9 shows the 10th, 50th, and 90th percentiles of beliefs, along with the mean and the best estimate of the true value, from the yellow tags. The first question in Table 9 shows that consumers' mean beliefs about water heater energy costs are approximately in line with the yellow tags. The second question, however, suggests that the mean and median consumers actually overestimate the average dollar value of potential cost savings. The third question takes the ratio of the second question to the first, which translates to a percent savings and can account for heterogeneity in consumers' utilization. The "true" mean energy cost savings on the yellow tags are about 10 percent, while the median and mean consumers report believing that Energy Star could save 25 and 32 percent, respectively 15 Of course, the beliefs

\footnotetext{
${ }^{15}$ Additional (unreported) regressions show that confusion about Energy Star purchases and beliefs about Energy Star savings do not vary across treatment groups, although estimates are imprecise.
} 
were elicited in a phone survey and not made incentive compatible, so they should be interpreted cautiously. Notwithstanding, they suggest that underestimating energy cost savings is not a barrier to Energy Star takeup.

\section{Conclusion}

Imperfect information is an oft-cited reason why regulators intervene in markets for energy-using durables though mandatory information disclosure, subsidies, and standards. In theory, one natural way for consumers to learn about the benefits of energy efficient products is through retailers. Motivated by this, we partnered with a large nationwide retailer to test the effects of information provision, customer rebates, and sales incentives on the behavior of both sales agents and consumers. We also present a simple model which, while not a theoretical advance per se, helps to motivate the experiment and clarify the results.

Results show that retailer-provided information is ineffective at increasing Energy Star demand, even after adjusting for partial compliance by sales agents. Knowing that information would be ineffective, sales agents appear to have marketed Energy Star to only the most receptive consumers, strategically failing to provide information to the majority. Follow-up surveys provide some evidence that at least some consumers who bought from the Retailer are unaware of the Energy Star product or confused about what they have bought. The majority of consumers who bought from the Retailer and completed our survey, however, are aware of Energy Star and may even overestimate its benefits. These results highlight the difficulties that retailers can face in increasing demand for energy efficient or otherwise "high-quality" products. In this context, a key difficulty appears to be that many consumers still don't view energy efficiency as a privately-beneficial investment, even after the retailer's attempts to inform them.

The water heater market has some unusual features, and our sample comprises only a small share of that market. What broader lessons can be drawn from our results? First, our results fit into a broader set of results from the literature suggesting that while social comparisons or various forms of persuasion can motivate pro-environmental behaviors, hard information about energy costs seems to have more limited effects. As our model makes clear, "hard" information about product availability (as well as product costs and benefits) is more relevant from a welfare perspective because a regulator's inability to address imperfect information could justify corrective policies, while the welfare implications of persuasion are less clear. Our experimental design does not allow us to cleanly distinguish whether consumers are more generally uninformed or whether they are simply disinterested in information from the retailer's agents. Notwithstanding, our survey results help somewhat to resolve this question. Furthermore, the water heater market is certainly one where consumers begin the process with very little information and do rely on agents' knowledge for many other aspects of the purchase. 
Second, our theoretical and empirical results clearly suggest that policymakers interested in maximizing the effects of subsidy dollars on Energy Star purchases might consider allocating some incentives to sales agents, not just to consumers. While the magnitude of our effect size is certainly specific to our context, this general suggestion is novel. Third, our results provide unusually granular insight into the role of sales agents in the process of information disclosure. In many situations like ours, a firm or policymaker must consider how to incentivize agents if they want to increase information disclosure. In equilibrium, firms and policymakers can also potentially learn about the value of information from whether experienced sales agents choose to provide it. 


\section{References}

[1] Allcott, Hunt (2011). "Social Norms and Energy Conservation." Journal of Public Economics, Vol. 95, No. 9-10 (October), pages 1082-1095.

[2] Allcott, Hunt (2013). "The Welfare Effects of Misperceived Product Costs: Data and Calibrations from the Automobile Market." American Economic Journal: Economic Policy, Vol. 5, No. 3 (August), pages $30-66$.

[3] Allcott, Hunt, and Todd Rogers (2014). "The Short-Run and Long-Run Effects of Behavioral Interventions: Experimental Evidence from Energy Conservation." American Economic Review, forthcoming.

[4] Allcott, Hunt, and Dmitry Taubinsky (2015). "Evaluating Behaviorally-Motivated Policy: Experimental Results from the Lightbulb Market." American Economic Review, forthcoming.

[5] Anagol, Santosh, Shawn Cole, and Shayak Sarkar. "Understanding the Advice of CommissionsMotivated Agents: Evidence from the Indian Life Insurance Market." Harvard Business School Working Paper, No. 12-055, (March 2013.)

[6] Anderson, Dennis, and John Claxton (1982). "Barriers to Consumer Choice of Energy Efficient Products." Journal of Consumer Research, Vol. 9, No. 2 (September), pages 163-170.

[7] Angrist, Joshua, and Jorn-Steffen Pischke (2012). "Probit better than LPM?" Available from http://www.mostlyharmlesseconometrics.com/2012/07/probit-better-than-lpm/

[8] Ashraf, Nava, Oriana Bandiera, and Kelsey Jack (2012). "No Margin, No Mission? A Field Experiment on Incentives for Pro-Social Tasks." SSRN Working Paper No. 2013825 (February).

[9] Bandiera, Oriana, Iwan Barankay, and Imran Rasul (2005). "Social Preferences and the Response to Incentives: Evidence from Personnel Data." Quarterly Journal of Economics, Vol. 120, No. 3 (August), pages 917-962.

[10] Bandiera, Oriana, Iwan Barankay, and Imran Rasul (2009). "Social Connections and Incentives in the Workplace: Evidence from Personnel Data." Econometrica, Vol. 77, No. 4, pages 1047-1094.

[11] Bandiera, Oriana, Iwan Barankay, and Imran Rasul (2010). "Social Incentives in the Workplace." Review of Economic Studies, Vol. 77, No. 2 (April), pages 417-458.

[12] Bandiera, Oriana, and Imran Rasul (2006). "Social Networks and Technology Adoption in Northern Mozambique." The Economic Journal, Vol. 116, No. 514, pages 869-902.

[13] Barankay, Iwan (2012). "Rank Incentives: Evidence from a Randomized Workplace Experiment." Working Paper, Wharton (July).

[14] Becker, Gary, and Kevin Murphy (1993). "A Simple Theory of Advertising as a Good or Bad." Quarterly Journal of Economics, Vol. 108, No. 4 (November), pages 941-964.

[15] Bhargava, Saurabh, and Dayanand Manoli (2013). "Why Are Benefits Left on the Table? Assessing the Role of Information, Complexity, and Stigma on Take-up with an IRS Field Experiment." Working Paper, University of Texas at Austin.

[16] BLS (Bureau of Labor Statistics) (2014). "Consumer Expenditure Survey: 2011 Expenditure Tables." Available from http://www.bls.gov/cex/csxstnd.htm

[17] Bollinger, Brian, Phillip Leslie, and Alan Sorensen (2011). "Calorie Posting in Chain Restaurants." American Economic Journal: Economic Policy, Vol. 3, No. 1 (February), pages 91-128.

[18] Brandon, Alec, John List, Robert Metcalfe, Michael Price (2014). "What Dives the Adoption of Energy Efficient Technologies? The Role of Social Information and Advertisements." Working Paper, University of Chicago (April). 
[19] Chan, Tat, Jia Li, and Lamar Pierce (2014). "Compensation and Peer Effects in Competing Sales Teams." Management Science, forthcoming.

[20] Chatterji, Aaron, Michael Findley, Nathan Jensen, Stephan Meier, and Daniel Nielson (2015). "Field Experiments in Strategy Research." Strategic Management Journal, forthcoming.

[21] Choi, James, David Laibson, and Brigitte Madrian (2010). "Why Does the Law of One Price Fail? An Experiment on Index Mutual Funds." Review of Financial Studies, Vol. 23, No. 4, pages 1405-1432.

[22] Davis, Lucas, and Gilbert Metcalf (2014). "Does Better Information Lead to Better Choices? Evidence from Energy-Efficiency Labels." NBER Working Paper No. 20720 (November).

[23] Deutsch, Matthias (2010a). "Life Cycle Cost Disclosure, Consumer Behavior, and Business Implications: Evidence from an Online Field Experiment." Journal of Industrial Ecology, Vol. 14, No. 1, pages 103-120.

[24] Deutsch, Matthias (2010b). "The Effect of Life-Cycle Cost Disclosure on Consumer Behavior: Evidence from a Field Experiment with Cooling Appliances." Energy Efficiency, Vol. 3, pages 303-315.

[25] DEHWA (Australian Department of the Environment, Water, Heritage, and the Arts) (2008). "Regulatory Impact Statement: Proposal to PhaseOut Inefficient Incandescent Light Bulbs." http://www.energyrating.gov.au/wpcontent/uploads/Energy_Rating_Documents/Library/Lighting/Incandescent_Lamps/200808-risphaseout.pdf

[26] Dixit, Avinash, and Victor Norman (1978). "Advertising and Welfare." Bell Journal of Economics, Vol. 91, No. 1 (April), pages 1-17.

[27] DOE (U.S. Department of Energy) (2010). Energy Star Water Heater Market Profile." Available from https://www.energystar.gov/ia/partners/prod_development/new_specs/downloads/water_heaters/Water_Heater_Marke

[28] Dolan, Paul, and Robert Metcalfe (2013). "Neighbors, Knowledge, and Nuggets: Two Natural Field Experiments on the Role of Incentives on Energy Conservation." CEP Discussion Paper No. 1222 (June).

[29] Dorfman, Robert, and Peter Steiner (1954). "Optimal Advertising and Optimal Quality." American Economic Review, Vol. 44, No. 5 (December), pages 826-836.

[30] Dranove, David, and Ginger Zhe Jin (2010). "Quality Disclosure and Certification: Theory and Practice." Journal of Economic Literature, Vol. 48, No. 4 (December), pages 935-963.

[31] Duarte, Fabian, and Justine Hastings (2012). "Fettered Consumers and Sophisticated Firms: Evidence from Mexico's Privatized Social Security Market." NBER Working Paper 18582 (November).

[32] Duflo, Esther, and Emmanuel Saez (2003). "The Role of Information and Social Interactions in Retirement Plan Decisions: Evidence from a Randomized Experiment." Quarterly Journal of Economics, Vol. 118, No. 3 (August), pages 815-842.

[33] Duflo, Esther, William Gale, Jeffrey Liebman, Peter Orszag, and Emmanuel Saez (2006). "Saving Incentives for Low- and Middle-Income Families: Evidence from a Field Experiment with H\&R Block." Quarterly Journal of Economics, Vol. 121, No. 4 (November), pages 1311-1346.

[34] Dupas, Pascaline (2011). "Do Teenagers Respond to HIV Risk Information? Evidence From a Field Experiment in Kenya," American Economic Journal: Applied Economics, Vol. 3, No. (January), pages $1-34$.

[35] Figlio, David, and Maurice E. Lucas (2004). "What's in a Grade? School Report Cards and the Housing Market." American Economic Review, Vol. 94, No. 3, pages 591-604.

[36] Fischer, Carolyn (2005). "On the Importance of the Supply Side in Demand-Side Management." Energy Economics, Vol. 27, No. 1 (January), pages 165-180. 
[37] Fischer, Carolyn (2010). "Imperfect Competition, Consumer Behavior, and the Provision of Fuel Efficiency in Light-Duty Vehicles." RFF Discussion Paper 10-60.

[38] Greenstone, Michael, Paul Oyer, and Annette Vissing-Jorgensen (2006). "Mandated Disclosure, Stock Returns, and the 1964 Securities Acts Amendments." Quarterly Journal of Economics, Vol. 121, No. 2, pages 399-460.

[39] Grossman, Gene, and Carl Shapiro (1984). "Informative Advertising with Differentiated Products." Review of Economic Studies, Vol. 51, No. 1 (January), pages 63-81.

[40] Hastings, Justine, and Jeffrey Weinstein (2008). "Information, School Choice, and Academic Achievement: Evidence from Two Experiments." Quarterly Journal of Economics, Vol. 123, No. 4, pages 1373-1414.

[41] Herberich, David, John List, and Michael Price (2011). "How Many Economists Does it Take to Change a Light Bulb? A Natural Field Experiment on Technology Adoption." Working Paper, University of Chicago (March).

[42] Hoffman, Florian, Roman Inderst, and Marco Ottaviani (2013). "Hypertargeting, Limited Attention, and Privacy: Implications for Marketing and Campaigning." Working Paper, Bocconi University (June).

[43] Houde, Sebastien (2014a). "How Consumers Respond to Environmental Certification and the Value of Energy Information." Working Paper, University of Maryland (March).

[44] Houde, Sebastien (2014b). "Bunching with the Stars: How Firms Respond to Environmental Certification." Working Paper, University of Maryland (February).

[45] Ichniowski, Casey, and Kathryn Shaw (2003). "Beyond Incentive Pay: Insiders' Estimates of the Value of Complementary Human Resource Management Practices." Journal of Economic Perspectives, Vol. 17, No. 1 (Winter), pages 155-180.

[46] Inderst, Roman, and Marco Ottaviani (2009). "Misselling Through Agents." American Economic Review, Vol. 99, No. 3, pages 883-908.

[47] Iyengar, Sheena, and Mark Lepper (2000). "When Choice is Demotivating: Can One Desire Too Much of a Good Thing?" Journal of Personality and Social Psychology, Vol. 79, No. 6, pages 995-1006.

[48] Jessoe, Katrina and David Rapson (2014). "Knowledge is (Less) Power: Experimental Evidence from Residential Energy Use." American Economic Review, Vol. 104, No. 4, pages 1417-1438.

[49] Jin, Ginger Zhe, and Phillip Leslie (2009). "Reputation Incentives for Restaurant Hygiene." American Economic Journal: Microeconomics, Vol. 1, No. 1 (February), pages 237-267.

[50] Jin, Ginger Zhe, and Alan Sorensen (2006). "Information and Consumer Choice: The Value of Publicized Health Plan Ratings." Journal of Health Economics, Vol. 25, No. 2, pages 248-275.

[51] Kallbekken, Steffen, Hakon Saelen, and Erlend Hermansen (2013). "Bridging the Energy Efficiency Gap: A Field Experiment on Lifetime Energy Costs and Household Appliances." Journal of Consumer Policy, Vol. 36, pages 1-16.

[52] Kahn, Matthew (2007). "Do Greens Drive Hummers? Environmental Ideology as a Determinant of Consumer Choice." Journal of Environmental Economics and Management, Vol. 54, No. 2 (September), pages 129-145.

[53] Kling, Jeffrey, Sendhil Mullainathan, Eldar Shafir, Lee Vermeulen, and Marian Wrobel (2012). "Comparison Friction: Experimental Evidence from Medicare Drug Plans." Quarterly Journal of Economics. Vol. 127, No. 1, pages 199-235.

[54] Larkin, Ian (2014) "'The Cost of High-Powered Incentives: Employee Gaming in Enterprise Software Sales." Journal of Labor Economics, forthcoming. 
[55] Lazear, Edward (2000). "Performance Pay and Productivity." American Economic Review, Vol. 90, No. 5 (December), pages 1346-1361.

[56] Leip, David (2013). "David Leip's Atlas of U.S. Presidential Elections." Available from http://uselectionatlas.org/

[57] Mantrala, Murali, Sonke Albers, Fabio Caldieraro, Ove Jensen, Kissan Joseph, Manfred Krafft, Chakravarthi Narasimhan, Srinath Gopalakrishna, Andris Zoltners, Rajiv Lal, and Leonard Lodish (2010). "Sales Force Modeling: State of the Field and Research Agenda." Marketing Letters, Vol. 21, No. 3, pages 255-272.

[58] Milgrom, Paul (2008). "What the Seller Won't Tell You: Persuasion and Disclosure in Markets." Journal of Economic Perspectives, Vol. 22, No. 2 (April), pages 115-132.

[59] Mullainathan, Sendhil, Markus Noeth, and Antoinette Schoar (2012). "The Market for Financial Advice: An Audit Study." NBER Working Paper No. 17929 (March).

[60] Nadel, Steven (2011). "Testimony of Steven Nadel, Executive Director, American Council for an EnergyEfficient Economy (ACEEE)." Before the Senate Energy and Natural Resources Committee, Hearing on Appliance Standards Regulation (March 10).

[61] Nagin, Daniel, James Rebitzer, Seth Sanders, and Lowell Taylor (2002). "Monitoring, Motivation, and Management: The Determinants of Opportunistic Behavior in a Field Experiment." American Economic Review, Vol. 92, No. 4 (September), pages 850-873.

[62] NHTSA (National Highway Traffic Safety Administration) (2010). "Final Regulatory Impact Analysis: Corporate Average Fuel Economy for MY 2012-MY 2016 Passenger Cars and Light Trucks." Office of Regulatory Analysis and Evaluation, National Center for Statistics and Analysis (March).

[63] Newell, Richard, and Juha Siikamaki (2013). "Nudging Energy Efficiency Behavior: The Role of Information Labels." Resources for the Future Discussion Paper 13-17 (July).

[64] Pope, Devin (2009). "Reacting to Rankings: Evidence from 'America's Best Hospitals."' Journal of Health Economics, Vol. 28, No. 6, pages 1154-1165.

[65] Scanlon, Dennis, Michael Chernew, Catherine McLaughlin, and Gary Solon (2002). "The Impact of Health Plan Report Cards on Managed Care Enrollment." Journal of Health Economics, Vol. 21 No. 1, pages 19-41.

[66] Shearer, Bruce (2004). "Piece Rates, Fixed Wages, and Incentives: Evidence from a Field Experiment." Review of Economic Studies, Vol. 71, No. 2, pages 513-534.

[67] Ward, David, Christopher D Clark, Kimberly L Jensen, Steven T Yen, Clifford S Russell (2011). "Factors influencing willingness-to-pay for the ENERGY STAR label." Energy Policy, Vol. 39 No. 3, pages 14501458. 


\section{Tables}

Table 1: Water Heater Model Overview

\begin{tabular}{lcccc}
\hline & \multicolumn{2}{c}{$\mathbf{4 0}$ Gallon } & \multicolumn{2}{c}{$\mathbf{5 0}$ Gallon } \\
\hline Warranty & 6 year & 12 year & 6 year & 12 year \\
& & & & \\
Price (\$) & & & & \\
Standard & 420 & 620 & 485 & 665 \\
Energy Star & 645 & 969 & 700 & 1020 \\
& & & & \\
Annual Energy Cost (\$ year) & 309 & 290 & 315 & 294 \\
Standard & 272 & 261 & 272 & 261 \\
Energy Star & & & & \\
& 6.1 & 12.0 & 5.0 & 10.8 \\
Undiscounted payback period (years) & $13 \%$ & $1 \%$ & $18 \%$ & $3 \%$ \\
IRR (at 13 year average life) & & & & \\
Market Share & $17.6 \%$ & $6.1 \%$ & $10.1 \%$ & $10.4 \%$ \\
Standard & $0.6 \%$ & $0.5 \%$ & $0.2 \%$ & $0.7 \%$ \\
Energy Star & & & & \\
\hline
\end{tabular}

Notes: This table presents information on the four different Energy Star natural gas water heater models sold by the Retailer, as well as their closest non-Energy Star substitutes. The standard and Energy Star 6-year warranty models are essentially undifferentiated other than price and energy use, while the 12-year warranty Energy Star models have other premium features.

Table 2: Experiment Timeline

\begin{tabular}{lcccccc}
\hline & & $\begin{array}{c}\text { Info, Rebates, } \\
\text { and Info x } \\
\text { Rebates }\end{array}$ & Spiff & $\begin{array}{c}\text { Spiff x } \\
\text { Rebates }\end{array}$ & $\begin{array}{c}\text { Consumers } \\
\text { Sample }\end{array}$ & Sales \\
\hline 1 & Dhase & Yes & & & 12,629 & 4,675 \\
2 & April 7-June 13 & Yes & Yes & & 7,254 & 2,523 \\
3 & June 14-July 6 & Yes & Yes & Yes & 1,974 & 715 \\
4 & July 7-July 26 & Yes & & & 1,490 & 362 \\
\hline
\end{tabular}


Table 3: Representativeness

\begin{tabular}{lccc}
\hline & $\begin{array}{c}\text { Sample } \\
\text { Mean }\end{array}$ & $\begin{array}{c}\text { Sample } \\
\text { Std. Dev. }\end{array}$ & $\begin{array}{c}\text { National } \\
\text { Average }\end{array}$ \\
\hline Zip Median Income (000s) & 71 & 27.3 & 56.9 \\
Home Value (000s) & 338 & 293 & 246 \\
College Grad & 0.61 & 0.43 & 0.32 \\
Age & 57.3 & 13.4 & 37.3 \\
Household Size & 3.2 & 1.5 & 2.4 \\
Democrat & 0.62 & 0.34 & 0.53 \\
Zip Hybrid Share (out of 100) & 1.3 & 1.1 & 0.94 \\
Acxiom Green Living & 0.31 & 0.46 & - \\
Acxiom Environmentalist & 0.14 & 0.35 & - \\
\hline
\end{tabular}

This table gives the mean and standard deviation of customer demographics. These variables are matched based on addresses and are thus available only for consumers who purchase water heaters. National average college graduate share is for people older than 25 years. National averages for the Acxiom Green Living and Environmentalist variables are not available. 
Table 4: Compliance by Treatment

\begin{tabular}{|c|c|c|c|c|c|c|c|}
\hline & $(1)$ & $(2)$ & $(3)$ & $(4)$ & $(5)$ & $(6)$ & $(7)$ \\
\hline Dependent Variable: & $\begin{array}{c}\text { Agent } \\
\text { Reported }\end{array}$ & $\begin{array}{l}\text { Mentioned } \\
\text { E-Star }\end{array}$ & Rebate & $\begin{array}{l}\text { Saves } \\
\text { Money }\end{array}$ & $\begin{array}{c}\text { Payback } \\
\text { Period }\end{array}$ & $\begin{array}{l}\text { Read } \\
\text { Script }\end{array}$ & $\begin{array}{l}\ln (\mathrm{E}-\mathrm{Star} \\
\text { Seconds) }\end{array}$ \\
\hline 1(Information Only) & $\begin{array}{c}0.481 \\
(0.010)^{* * *}\end{array}$ & $\begin{array}{c}0.108 \\
(0.037)^{* * *}\end{array}$ & $\begin{array}{c}0.028 \\
(0.013)^{* *}\end{array}$ & $\begin{array}{c}0.117 \\
(0.031)^{* * *}\end{array}$ & $\begin{array}{c}0.133 \\
(0.024)^{* * *}\end{array}$ & $\begin{array}{c}0.149 \\
(0.027)^{* * *}\end{array}$ & $\begin{array}{c}0.406 \\
(0.133)^{* * *}\end{array}$ \\
\hline 1(Info and 25 Rebate) & $\begin{array}{c}0.491 \\
(0.010)^{* * *}\end{array}$ & $\begin{array}{c}0.130 \\
(0.039)^{* * *}\end{array}$ & $\begin{array}{c}0.239 \\
(0.030)^{* * *}\end{array}$ & $\begin{array}{c}0.168 \\
(0.033)^{* * *}\end{array}$ & $\begin{array}{c}0.149 \\
(0.025)^{* * *}\end{array}$ & $\begin{array}{c}0.193 \\
(0.033)^{* * *}\end{array}$ & $\begin{array}{c}0.516 \\
(0.141)^{* * *}\end{array}$ \\
\hline 1(Info and 100 Rebate) & $\begin{array}{c}0.460 \\
(0.019)^{* * *}\end{array}$ & $\begin{array}{l}0.057 \\
(0.060)\end{array}$ & $\begin{array}{c}0.143 \\
(0.045)^{* * *}\end{array}$ & $\begin{array}{c}0.108 \\
(0.052)^{* *}\end{array}$ & $\begin{array}{c}0.093 \\
(0.036)^{* * *}\end{array}$ & $\begin{array}{c}0.156 \\
(0.057)^{* * *}\end{array}$ & $\begin{array}{l}0.337 \\
(0.232)\end{array}$ \\
\hline 1(25 Rebate Only) & $\begin{array}{c}0.491 \\
(0.006)^{* * *}\end{array}$ & $\begin{array}{c}0.147 \\
(0.025)^{* * *}\end{array}$ & $\begin{array}{c}0.182 \\
(0.018)^{* * *}\end{array}$ & $\begin{array}{l}0.019 \\
(0.016)\end{array}$ & $\begin{array}{l}0.000 \\
(0.005)\end{array}$ & $\begin{array}{c}0.214 \\
(0.020)^{* * *}\end{array}$ & $\begin{array}{c}0.509 \\
(0.089)^{* * *}\end{array}$ \\
\hline 1(100 Rebate Only) & $\begin{array}{c}0.494 \\
(0.010)^{* * *}\end{array}$ & $\begin{array}{c}0.143 \\
(0.037)^{* * *}\end{array}$ & $\begin{array}{c}0.190 \\
(0.031)^{* * *}\end{array}$ & $\begin{array}{c}0.061 \\
(0.027)^{* *}\end{array}$ & $\begin{array}{l}0.001 \\
(0.009)\end{array}$ & $\begin{array}{c}0.180 \\
(0.033)^{* * *}\end{array}$ & $\begin{array}{c}0.620 \\
(0.144)^{* * *}\end{array}$ \\
\hline 1(Spiff Only) & & $\begin{array}{l}0.027 \\
(0.024)\end{array}$ & $\begin{array}{c}0.032 \\
(0.010)^{* * *}\end{array}$ & $\begin{array}{l}0.008 \\
(0.016)\end{array}$ & $\begin{array}{l}-0.002 \\
(0.005)\end{array}$ & $\begin{array}{l}0.011 \\
(0.013)\end{array}$ & $\begin{array}{l}0.099 \\
(0.085)\end{array}$ \\
\hline 1(Spiff and 25 Rebate) & & $\begin{array}{l}0.051 \\
(0.050)\end{array}$ & $\begin{array}{c}0.092 \\
(0.035)^{* * *}\end{array}$ & $\begin{array}{c}0.073 \\
(0.044)^{*}\end{array}$ & $\begin{array}{l}-0.014 \\
(0.010)\end{array}$ & $\begin{array}{l}0.036 \\
(0.029)\end{array}$ & $\begin{array}{l}0.257 \\
(0.184)\end{array}$ \\
\hline 1(Spiff and 100 Rebate) & & $\begin{array}{l}0.063 \\
(0.067)\end{array}$ & $\begin{array}{c}0.172 \\
(0.064)^{* * *}\end{array}$ & $\begin{array}{l}0.107 \\
(0.066)\end{array}$ & $\begin{array}{c}-0.033 \\
(0.016)^{* *}\end{array}$ & $\begin{array}{c}0.155 \\
(0.065)^{* *}\end{array}$ & $\begin{array}{l}0.289 \\
(0.259)\end{array}$ \\
\hline $\begin{array}{l}R^{2} \\
N\end{array}$ & $\begin{array}{c}0.39 \\
20,240\end{array}$ & $\begin{array}{c}0.17 \\
2,068\end{array}$ & $\begin{array}{c}0.22 \\
2,068\end{array}$ & $\begin{array}{c}0.14 \\
2,068\end{array}$ & $\begin{array}{c}0.20 \\
2,067\end{array}$ & $\begin{array}{c}0.25 \\
1,742\end{array}$ & $\begin{array}{c}0.16 \\
2,068\end{array}$ \\
\hline Dep. Var. Control Mean & 0 & .13 & 0 & .05 & 0 & .01 & .41 \\
\hline
\end{tabular}

Notes: This table reports the estimates of Equation (9). All regressions include agent and phase indicator variables. Robust standard errors in parenthesis. *,**, ***: Statistically significant with 90, 95, and 99 percent confidence, respectively. 
Table 5: Information Treatment Agents vs. Information Control Agents

\begin{tabular}{|c|c|c|c|c|c|c|}
\hline & (1) & $(2)$ & $(3)$ & $(4)$ & $(5)$ & $(6)$ \\
\hline Dependent Variable: & $\begin{array}{c}\text { Agent } \\
\text { Reported }\end{array}$ & $\begin{array}{l}\text { Mentioned } \\
\text { E-Star }\end{array}$ & Rebate & $\begin{array}{l}\text { Saves } \\
\text { Money }\end{array}$ & $\begin{array}{l}\text { Read } \\
\text { Script }\end{array}$ & $\begin{array}{l}\ln (\text { E-Star } \\
\text { Seconds })\end{array}$ \\
\hline 1(Rebate) & $\begin{array}{l}-0.072 \\
(0.098)\end{array}$ & $\begin{array}{l}0.063 \\
(0.102)\end{array}$ & $\begin{array}{l}-0.048 \\
(0.085)\end{array}$ & $\begin{array}{l}0.045 \\
(0.029)\end{array}$ & $\begin{array}{l}0.005 \\
(0.100)\end{array}$ & $\begin{array}{l}0.189 \\
(0.339)\end{array}$ \\
\hline 1(Spiff Only) & & $\begin{array}{l}0.092 \\
(0.059)\end{array}$ & $\begin{array}{l}0.004 \\
(0.035)\end{array}$ & $\begin{array}{c}0.062 \\
(0.031)^{*}\end{array}$ & $\begin{array}{l}0.030 \\
(0.023)\end{array}$ & $\begin{array}{c}0.314 \\
(0.180)^{*}\end{array}$ \\
\hline 1(Spiff and Rebate) & & $\begin{array}{l}-0.143 \\
(0.144)\end{array}$ & $\begin{array}{l}-0.136 \\
(0.109)\end{array}$ & $\begin{array}{l}-0.076 \\
(0.122)\end{array}$ & $\begin{array}{l}-0.090 \\
(0.084)\end{array}$ & $\begin{array}{l}-0.555 \\
(0.532)\end{array}$ \\
\hline 1 (Control) & & $\begin{array}{c}0.109 \\
(0.052)^{* *}\end{array}$ & $\begin{array}{l}0.003 \\
(0.007)\end{array}$ & $\begin{array}{c}0.044 \\
(0.029)\end{array}$ & $\begin{array}{c}0.007 \\
(0.010)\end{array}$ & $\begin{array}{c}0.320 \\
(0.157)^{* *}\end{array}$ \\
\hline $\begin{array}{l}R^{2} \\
N\end{array}$ & $\begin{array}{c}0.01 \\
8,276\end{array}$ & $\begin{array}{c}0.04 \\
1,642\end{array}$ & $\begin{array}{c}0.09 \\
1,642\end{array}$ & $\begin{array}{c}0.02 \\
1,642\end{array}$ & $\begin{array}{c}0.11 \\
1,408\end{array}$ & $\begin{array}{c}0.04 \\
1,642\end{array}$ \\
\hline Dep. Var. Control Agent Mean & .527 & .178 & .101 & .051 & .101 & .582 \\
\hline
\end{tabular}

Notes: This table reports the estimates of $\gamma$ in Equation $(10)$. All regressions include phase and treatment group indicator variables. Robust standard errors, clustered by agent, in parenthesis. *, $* *, * * *$ : Statistically significant with 90,95 , and 99 percent confidence, respectively. 
Table 6: Treatment Effects

\begin{tabular}{lcccccc}
\hline & $(1)$ & $(2)$ & $(3)$ & $(4)$ & $(5)$ & $(6)$ \\
\hline Dependent Variable: & 1 (Sale) & 1 (Sale) & 1 (Sale) & 1 (EStar) & 1 (EStar) & 1 (EStar) \\
\hline 1 (100 Rebate) & -0.010 & -0.024 & 0.030 & 0.006 & 0.012 & 0.037 \\
& $(0.011)$ & $(0.022)$ & $(0.045)$ & $(0.003)^{* *}$ & $(0.005)^{* *}$ & $(0.013)^{* * *}$ \\
1 (25 Rebate) & -0.019 & -0.040 & -0.015 & 0.001 & 0.002 & 0.003 \\
& $(0.007)^{* * *}$ & $(0.015)^{* * *}$ & $(0.029)$ & $(0.001)$ & $(0.003)$ & $(0.005)$ \\
1 (Information) & -0.005 & -0.009 & -0.059 & 0.000 & 0.000 & 0.004 \\
& $(0.009)$ & $(0.020)$ & $(0.036)$ & $(0.002)$ & $(0.004)$ & $(0.007)$ \\
1 (Spiff) & 0.007 & & 0.025 & -0.002 & & 0.001 \\
& $(0.012)$ & & $(0.042)$ & $(0.002)$ & & $(0.007)$ \\
1 (Spiff and 25 Rebate) & 0.000 & & 0.055 & -0.004 & & -0.007 \\
& $(0.032)$ & & $(0.111)$ & $(0.002)^{* *}$ & & $(0.005)$ \\
1 (Spiff and 100 Rebate) & 0.041 & & 0.200 & 0.040 & & 0.219 \\
& $(0.053)$ & & $(0.193)$ & $(0.022)^{*}$ & & $(0.118)^{*}$ \\
$R^{2}$ & 0.02 & 0.02 & 0.02 & 0.01 & 0.01 & 0.01 \\
$N$ & 23,347 & 20,240 & 23,347 & 23,347 & 20,240 & 23,347 \\
Dep. Var. Control Mean & .364 & .364 & .364 & .009 & .009 & .009 \\
Regression Type: & ITT & Self- & Scaled & ITT & Self- & Scaled \\
& & Report IV & ITT & & Report IV & ITT \\
\hline
\end{tabular}

Notes: This table reports the estimates of Equation (11). All regressions contain agent and period indicator variables. Robust standard errors in parenthesis. ${ }^{*}, * *, * * *$ Statistically significant with 90, 95, and 99 percent confidence, respectively. 
Table 7: Targeted Information Provision

\begin{tabular}{lcccc}
\hline & $(1)$ & $(2)$ & $(3)$ & $(4)$ \\
\hline Dependent Variable: & 1(Factor) & 1(EStar) & 1(EStar) & 1(EStar) \\
\hline T x Agent Reported Compliance & -0.014 & 0.013 & 0.038 & 0.034 \\
& $(0.030)$ & $(0.002)^{* * *}$ & $(0.007)^{* * *}$ & $(0.006)^{* * *}$ \\
T x (1 - Agent Reported Compliance) & -0.057 & -0.009 & -0.031 & -0.022 \\
& $(0.021)^{* * *}$ & $(0.001)^{* * *}$ & $(0.005)^{* * *}$ & $(0.004)^{* * *}$ \\
$R^{2}$ & 0.18 & 0.02 & 0.05 & 0.05 \\
$N$ & 404 & 20,240 & 5,180 & 6,123 \\
Dep. Var. Control Mean & .061 & .009 & .033 & .025 \\
\hline
\end{tabular}

Notes: This table reports the estimates of Equation (12). All regressions contain agent and period indicator variables. Robust standard errors in parenthesis. ${ }^{*}, * *, * * *$ Statistically significant with 90, 95, and 99 percent confidence, respectively.

Table 8: Survey Results: Energy Star Purchases

\begin{tabular}{lc}
\hline Self-Reported Energy Star Purchase & \\
Some water heater models that use less energy are officially designated as Energy Star. \\
Did you buy an Energy Star model? & Percent \\
Response & 52 \\
Yes & 24 \\
No & 24 \\
Not sure & 2.1 \\
True Energy Star share in survey sample & \\
& \\
Reasons to Not Purchase Energy Star & an Energy Star model? \\
Why did you decide to buy a standard, non-Energy Star model over ant & Percent \\
Response & 33.3 \\
Upfront price too high & 15.4 \\
I was not aware that there was an Energy Star option & 8 \\
Energy Star not in stock & 5.9 \\
Needed a short tank & 2.8 \\
No electrical outlet & 2.3 \\
Needed low-NOx & 1.4 \\
Wanted longer warranty & 1.2 \\
Non-Energy Star heats water faster & 30.7 \\
Other
\end{tabular}

This table presents responses to two questions from our follow-up survey of consumers who purchased from the Retailer. Sample size for the first question is 891. The second question was asked only of people who thought they had not purchased an Energy Star model or were not sure but in fact had not; sample size is 423 . 


\section{Table 9: Survey Results: Beliefs About Energy Star}

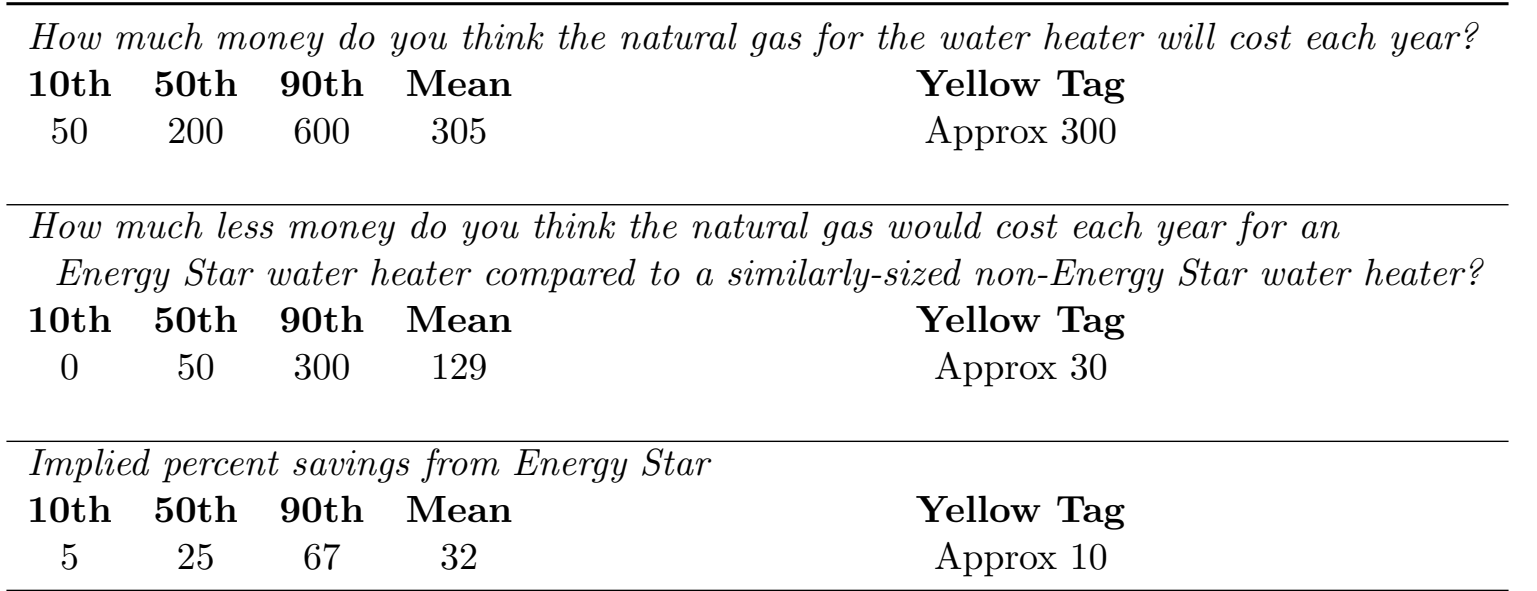

This table presents responses to three questions from our follow-up survey of consumers who purchased from the Retailer. Sample size is 891. 


\section{Figures}

Figure 1: CDF of Audited Compliance

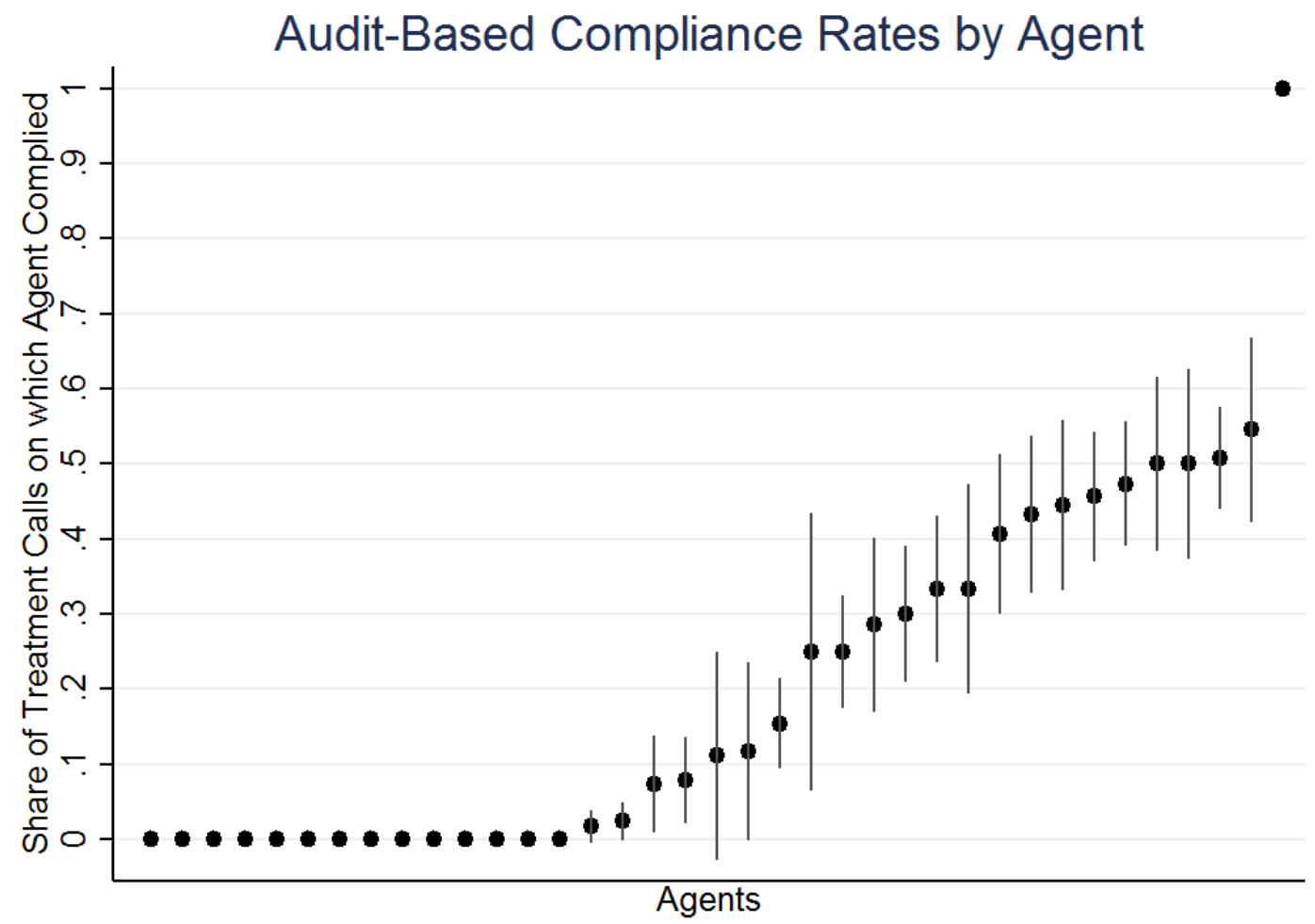

Notes: This figure plots the average compliance rate on all calls other than Spiff Only and control group calls, for all agents that were audited more than five times. Compliance is measured by an indicator variable $N_{i a}^{+}$that takes value 1 if an agent read a script, mentioned an Energy Star rebate on a rebate call, or quoted a payback period on an information call. 


\section{Online Appendix: Not for Publication}

Can Retailers Inform Consumers about Energy Costs? Evidence from a Field Experiment

Hunt Allcott and Richard Sweeney 


\section{A Proofs of Theoretical Results}

\section{Proof of Proposition 3}

The comparative static can be derived by simply writing out $q_{f E}\left(p_{f E}, \tilde{\theta}_{f}\left(p_{f E}, s_{f}\right)\right.$ and taking derivatives. Consider firm 1:

$$
q_{1 E}\left(p_{1 E}, \tilde{\theta}_{1}\left(p_{1 E}, s_{1}\right)=\lambda \tilde{\theta}_{1}\left[\left(1-\theta_{2}\right)+\theta_{2} \frac{p_{2 E}+t-p_{1 E}}{2 t}\right]\right.
$$

Substituting $\tilde{\theta}_{1}$ from Equation 22 gives:

$$
q_{1 E}\left(p_{1 E}, \tilde{\theta}_{1}\left(p_{1 E}, s_{1}\right)=\frac{s_{1} \lambda^{2}}{\alpha}\left[\left(1-\theta_{2}\right)+\theta_{2} \frac{p_{2 E}+t-p_{1 E}}{2 t}\right]^{2}\right.
$$

Taking derivatives gives:

$$
\begin{gathered}
\frac{\partial q_{1 E}}{\partial s_{1}}=\frac{\lambda^{2}}{\alpha}\left[\left(1-\theta_{2}\right)+\theta_{2} \frac{p_{2 E}+t-p_{1 E}}{2 t}\right]^{2}>0 \\
\frac{\partial q_{1 E}}{\partial p_{1 E}}=-\frac{s_{1} \lambda^{2}}{\alpha} \cdot \frac{\theta_{2}}{t}\left[\left(1-\theta_{2}\right)+\theta_{2} \frac{p_{2 E}+t-p_{1 E}}{2 t}\right]<0 \\
\frac{\partial^{2}{ }_{1 E}}{\partial s_{1} \partial p_{1 E}}=-\frac{\lambda^{2}}{\alpha} \cdot \frac{\theta_{2}}{t}\left[\left(1-\theta_{2}\right)+\theta_{2} \frac{p_{2 E}+t-p_{1 E}}{2 t}\right]<0
\end{gathered}
$$

\section{Derivation of Market Equilibrium}

Using Equation [4], we now solve for the firm's optimal prices and the optimal $\theta_{f}$ that the firm would like to induce.

We first solve for the symmetric equilibrium prices, which are identical to the standard textbook model. The first order condition (FOC) for $p_{1 I}$ is:

$$
\frac{\partial \pi_{1}}{\partial p_{1 I}}=d_{I}-\frac{1}{2 t}\left(p_{1 I}-c_{I}\right)=0
$$

This is the usual FOC for the textbook two-firm Hotelling model: increasing $p_{1 I}$ increases revenues from the share $d_{I}$ of consumers who purchase from firm 1, but quantity sold decreases by an amount inversely proportional to the transport cost.

The FOC for $p_{1 E}$ is:

$$
\frac{\partial \pi_{1}}{\partial p_{1 E}}=\lambda\left[\theta_{1}\left(1-\theta_{2}\right)+\theta_{1} \theta_{2}\left(d_{E}-\frac{1}{2 t}\left(p_{1 E}-c_{E}\right)\right)\right]
$$

This FOC is also standard to models like Grossman and Shapiro (1984). Raising $p_{1 E}$ increases revenues from the share of High type consumers that are informed only by firm 1, and none of these consumers substitute to firm 2 because they are unaware that firm 2 sells good $E$. Share $\theta_{1} \theta_{2}$ are informed by both firms, and increasing $p_{1 E}$ increases revenues from the share that buy from firm 1 but decreases that share by an amount inversely proportional to the transport cost.

Simplifying Equation 16 gives $p_{1 I}^{*}=\frac{p_{2 I}^{*}+c_{I}+t}{2}$. Imposing symmetry and solving gives $p_{1 I}^{*}=p_{2 I}^{*}=c_{I}+t$. Simplifying Equation 17 gives $p_{1 E}^{*}=2 t \frac{\left(1-\theta_{2}\right)}{\theta_{2}}+2 t d_{E}+c_{E}$. Imposing symmetry and solving gives $p_{1 E}^{*}=$ $p_{2 E}^{*}=c_{E}+\left(\frac{2}{\theta}-1\right) t$. 
The FOC for $\theta_{1}$ is:

$$
\frac{\partial \pi_{1}}{\partial \theta_{1}}=\lambda\left\{\left(p_{1 E}-c_{E}\right)\left[\left(1-\theta_{2}\right)+d_{E} \theta_{2}\right]-\left(1-\theta_{2}\right) d_{I}\left(p_{1 I}-c_{I}\right)\right\}-\alpha \theta_{1}
$$

Increasing $\theta_{1}$ induces more High type consumers to purchase good $E$ but cannibalizes sales of good $I$. The first term inside the brackets represents increased profits from sales of good $E$, but the second term shows decreased profits from good $I$.

The FOCs for firm 2 are again symmetric after replacing $d_{I}$ and $d_{E}$ with $1-d_{I}$ and $1-d_{E}$, respectively. To solve for the symmetric equilibrium information provision level, set Equation 18 to zero and re-arrange:

$$
\left(p_{1 E}-c_{E}\right)\left[\left(1-\theta_{2}\right)+d_{E} \theta_{2}\right]-\left(1-\theta_{2}\right) d_{I}\left(p_{1 I}-c_{I}\right)=\frac{\alpha}{\lambda} \theta_{1}
$$

Imposing symmetry and simplifying gives

$$
\left(1-\frac{\theta^{*}}{2}\right)\left(p_{E}^{*}-c_{E}\right)-\frac{1}{2}\left(1-\theta^{*}\right)\left(p_{I}^{*}-c_{I}\right)=\frac{\alpha}{\lambda} \theta^{*}
$$

Substituting in the equilibrium prices gives:

$$
\left(1-\frac{\theta^{*}}{2}\right) t\left(\frac{2}{\theta^{*}}-1\right)-\frac{t}{2}\left(1-\theta^{*}\right)=\frac{\alpha}{\lambda} \theta^{*}
$$

Upon simplification, we have:

$$
\left(\frac{\alpha}{\lambda t}-1\right) \theta^{* 2}+\frac{5}{2} \theta^{*}-2=0
$$

Of the two roots of this quadratic equation, only one gives systematically positive values of $\theta$. This is $\theta^{*}=\frac{-5+\sqrt{32 \frac{\alpha}{\lambda t}-7}}{4\left(\frac{\alpha}{\lambda t}-1\right)}$, which is decreasing in $\alpha$ and increasing in $\lambda$ and $t$.

\section{Socially-Optimal Information Provision}

In the case of energy-using durables, the U.S. Department of Energy facilitates and encourages retailer information disclosure through the Energy Star Retail Partnership program. Imagine that the social planner could induce firms to undertake any symmetric amount of information provision. Taking the derivative of Equation (5), the socially optimal level of symmetric information provision would satisfy the following first order condition:

$$
\frac{\partial S W}{\partial \theta_{f}}=\lambda\left(2-2 \theta_{f}\right)\left(G_{H E}-G_{I}\right)-2 \alpha \theta_{f}
$$

The first term is the gain from inducing an additional High type consumer to purchase good $E$. The second term is the marginal cost of information. The socially-optimal symmetric information provision level $\theta_{f}^{+}$is thus:

$$
\theta_{f}^{+}=\frac{G_{H E}-G_{I}}{G_{H E}-G_{I}+\frac{\alpha}{\lambda}}
$$

Optimal information provision is higher when the social gain from moving a High type consumer to good $E$ is larger, when there are a larger share of High types in the population, and when advertising costs are 
smaller. Depending on the value of $G_{H E}-G_{I}, \theta_{f}^{+}$could be anywhere between 0 and 1 , regardless of the values of other parameters. Thus, it is ambiguous whether the market equilibrium $\theta_{f}^{*}$ over- or under-provides information relative to $\theta_{f}^{+}$. Notwithstanding, only $\theta_{f}^{+}$is a function of $G_{H E}-G_{I}$, while only $\theta_{f}^{*}$ is a function of $t$. Thus, the market is more likely to under-provide information when the social gain $G_{H E}-G_{I}$ from moving consumers to good $E$ is large or when market power $t$ is small.

\section{Socially-Optimal Government-Provided Sales Incentive}

Assume that $\theta_{f}^{+}>\theta_{f}^{*}$ and assume that the government has provided a sales incentive $s^{+}$to induce sociallyoptimal information provision $\theta^{+}$. We know that the firm would not provide an additional positive sales incentive given that $s^{+}$is already larger than the profit-maximizing level. The participation constraint again pins down $w_{1}$. Substituting the participation constraint into firm 1's profit function gives:

$$
\pi_{1}\left(p_{1 I}, p_{1 E}\right)=q_{1 I}\left(p_{1 I}, \theta^{+}\right)\left[p_{1 I}-c_{I}\right]+q_{1 E}\left(p_{1 E}, \theta^{+}\right)\left[p_{1 E}-c_{E}-s^{+}\right]-\left[\bar{U}-s^{+} q_{1 E}\left(p_{1 E}, \theta^{+}\right)+\frac{\alpha}{2}\left(\theta^{+}\right)^{2}\right] .
$$

The price first-order conditions in Equations (16) and (17) above are unchanged, so the profit maximizing prices are determined by the same formulas. The one difference is that $\theta_{f}=\theta_{f}^{+}$, and since $\theta_{f}^{+}>\theta_{f}^{*}, p_{f E}$ decreases relative to the original market equilibrium. 


\section{B Appendix: Additional Tables and Figures}

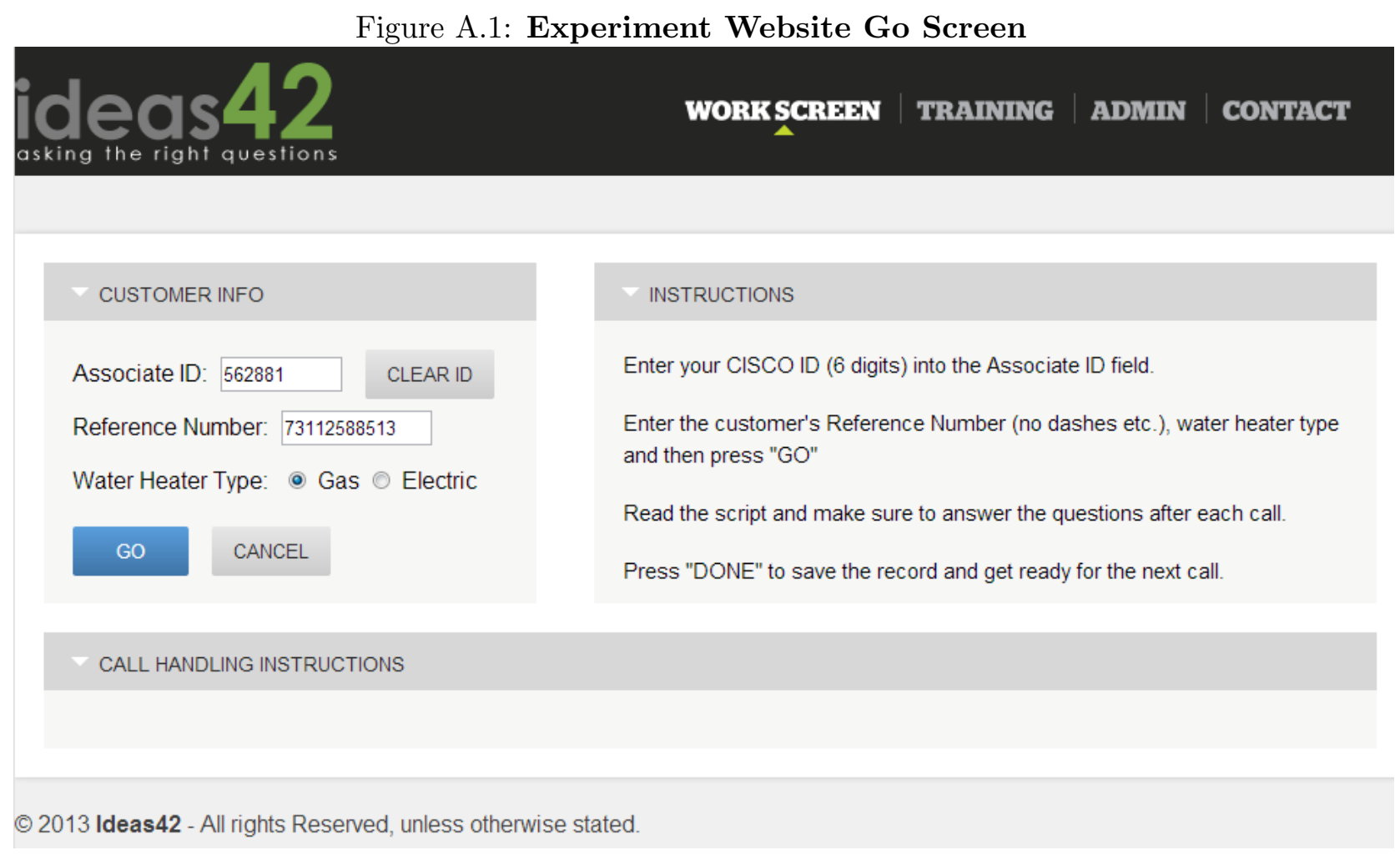


Figure A.2: Experiment Website $\$ 100$ Rebate Screen

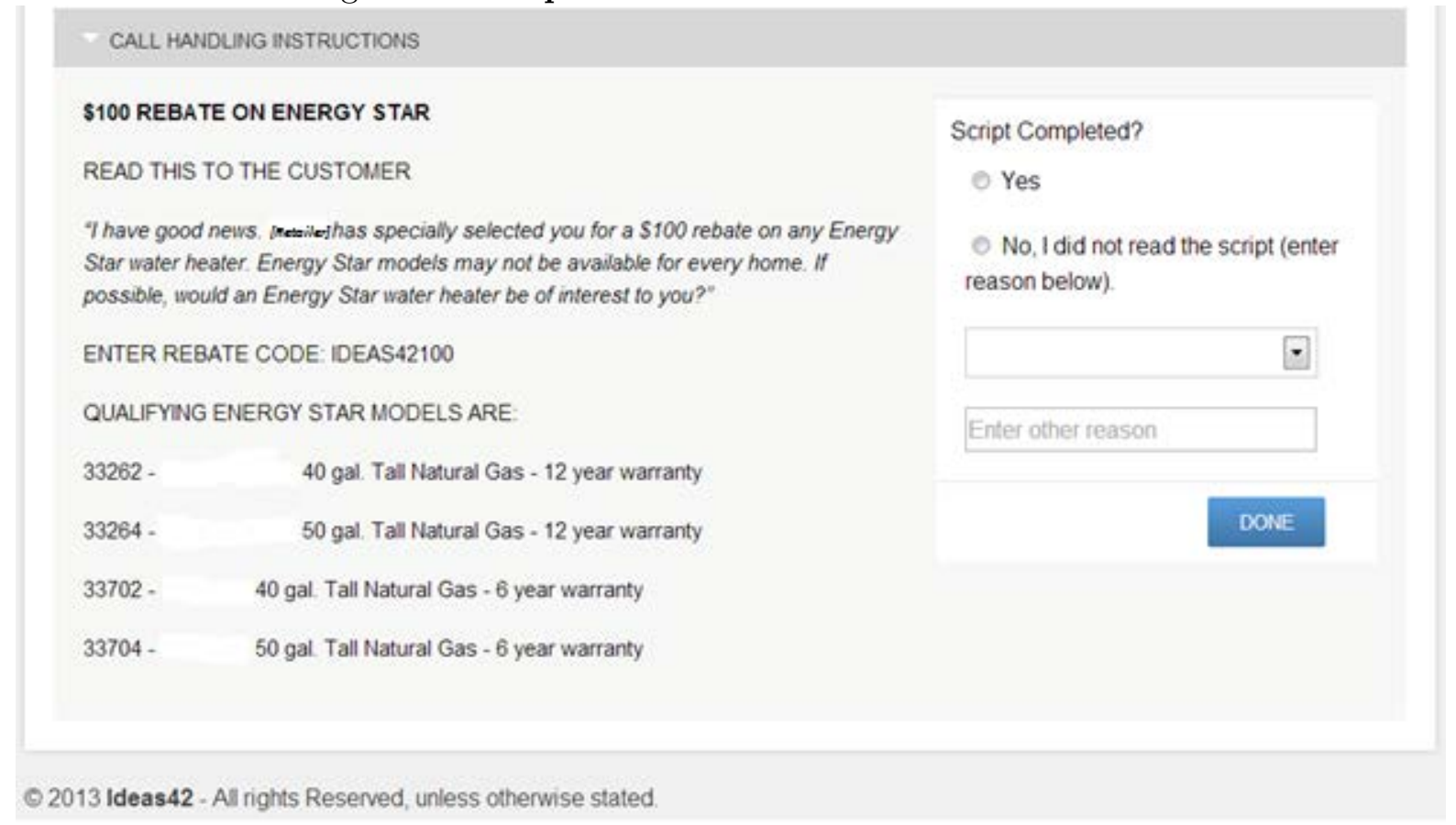




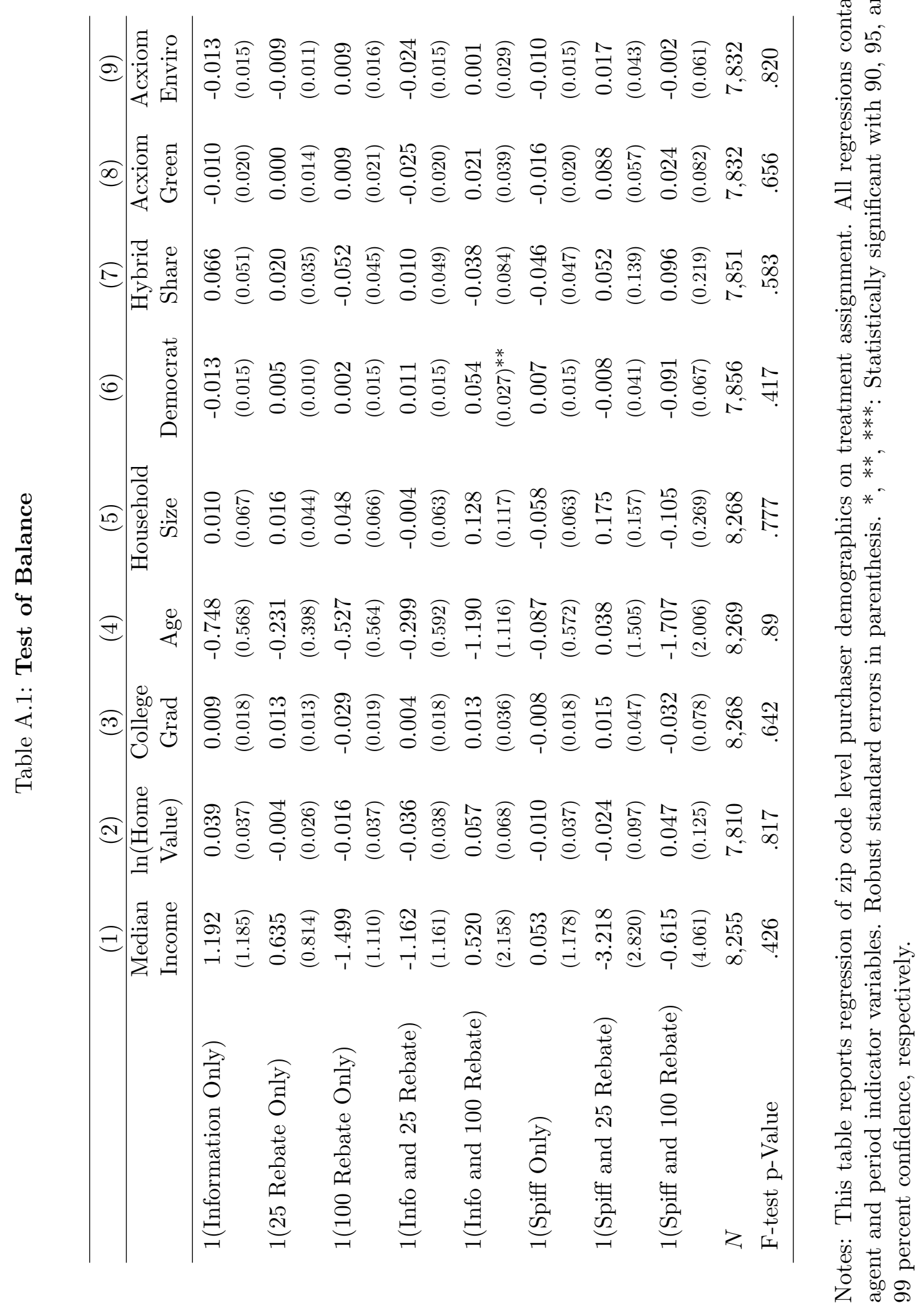


Table A.2: Treatment Effects: Alternative Estimates

\begin{tabular}{lccc}
\hline & $(1)$ & $(2)$ & $(3)$ \\
\hline Outcome: & $1($ Sale $)$ & $1($ Sale $)$ & 1 (EStar) \\
\hline $1(100$ Rebate) & -0.020 & 0.013 & 0.064 \\
& $(0.013)$ & $(0.020)$ & $(0.024)^{* * *}$ \\
1 (25 Rebate) & -0.027 & -0.001 & 0.003 \\
& $(0.009)^{* * *}$ & $(0.013)$ & $(0.010)$ \\
1(Information) & 0.002 & -0.021 & 0.006 \\
& $(0.011)$ & $(0.016)$ & $(0.013)$ \\
1 (Spiff) & 0.006 & 0.011 & -0.000 \\
& $(0.015)$ & $(0.019)$ & $(0.013)$ \\
1(Spiff and 25 Rebate) & -0.027 & 0.044 & -0.015 \\
& $(0.041)$ & $(0.053)$ & $(0.010)$ \\
1(Spiff and 100 Rebate) & -0.008 & 0.136 & 0.405 \\
& $(0.064)$ & $(0.092)$ & $(0.221)^{*}$ \\
$R^{2}$ & 0.02 & 0.02 & 0.01 \\
$N$ & 16,117 & 7,230 & 23,347 \\
Dep. Var. Control Mean & .366 & .358 & .009 \\
Regression Type: & ITT & ITT & Scaled \\
& & & ITT \\
Sample: & Non-Compliant & Compliant & All \\
& Agents & Agents & Consumers \\
\hline
\end{tabular}

Notes: This table reports the estimates of Equation (11), as alternative specifications to Table 6. Columns 1 and 2 are comparable to column 1 of Table 6, except splitting the sample to noncompliant agents (the lower two compliance groups) and compliant agents (the higher two compliance groups). Column 3 is comparable to column 6 of Table 6 , except that $G_{i a}$ is based on each compliance group's average difference in Mentioned E-Star between treatment and control calls. All regressions contain agent and period indicator variables. Robust standard errors in parenthesis. $*$, **, ***: Statistically significant with 90, 95, and 99 percent confidence, respectively. 
Table A.3: Treatment Effects in the Sample Purchasing Substitutable Models

\begin{tabular}{lcccccc}
\hline & $(1)$ & $(2)$ & $(3)$ & $(4)$ & $(5)$ & $(6)$ \\
\hline Dependent Variable: & $1($ EStar $)$ & 1 (EStar) & 1 (EStar) & 1 (EStar) & 1 (EStar) & $1($ EStar $)$ \\
\hline $1(100$ Rebate) & 0.023 & 0.042 & 0.100 & 0.021 & 0.042 & 0.098 \\
& $(0.010)^{* *}$ & $(0.017)^{* *}$ & $(0.035)^{* * *}$ & $(0.011)^{* *}$ & $(0.019)^{* *}$ & $(0.038)^{* * *}$ \\
$1(25$ Rebate) & 0.006 & 0.013 & 0.010 & 0.007 & 0.014 & 0.009 \\
& $(0.005)$ & $(0.009)$ & $(0.015)$ & $(0.006)$ & $(0.010)$ & $(0.016)$ \\
1 (Information) & 0.001 & -0.000 & 0.016 & -0.001 & -0.003 & 0.014 \\
& $(0.006)$ & $(0.012)$ & $(0.020)$ & $(0.007)$ & $(0.013)$ & $(0.022)$ \\
1 (Spiff) & -0.010 & & -0.001 & -0.009 & & -0.003 \\
& $(0.008)$ & & $(0.019)$ & $(0.008)$ & & $(0.021)$ \\
1 (Spiff and 25 Rebate) & -0.020 & & -0.023 & -0.025 & & -0.026 \\
& $(0.009)^{* *}$ & & $(0.018)$ & $(0.013)^{* *}$ & & $(0.028)$ \\
1 (Spiff and 100 Rebate) & 0.198 & & 0.536 & 0.254 & & 0.614 \\
& $(0.093)^{* *}$ & & $(0.242)^{* *}$ & $(0.108)^{* *}$ & & $(0.260)^{* *}$ \\
$R^{2}$ & 0.04 & 0.04 & 0.04 & 0.12 & 0.13 & 0.13 \\
$N$ & 6,000 & 5,180 & 6,000 & 6,000 & 5,180 & 6,000 \\
Dep. Var. Control Mean & .033 & .033 & .033 & .033 & .033 & .033 \\
Regression Type: & ITT & Self- & Scaled & ITT & Self- & Scaled \\
& & Report IV & ITT & & Report IV & ITT \\
Controls: & Base & Base & Base & Zip3 & Zip3 & Zip3 \\
\hline
\end{tabular}

Notes: This table reports the estimates of Equation (11) in the sample of consumers that purchased substitutable models. In the Scaled ITT, the average compliance $G_{i a}$ is calculated only within the sample of calls by consumers who purchase substitutable models. All regressions contain agent and period indicator variables, and columns 4-6 additionally include a vector of three-digit zip code indicators. Robust standard errors in parenthesis. *, **,***: Statistically significant with 90, 95, and 99 percent confidence, respectively. 
Table A.4: Treatment Effects: Probit Estimates

\begin{tabular}{lcccc}
\hline Column in Table 6: & $(1)$ & $(3)$ & $(4)$ & $(6)$ \\
\hline Dependent Variable: & $1($ Sale $)$ & 1 (Sale) & 1 (EStar) & 1 (EStar) \\
\hline 1(100 Rebate) & -0.028 & 0.079 & 0.185 & 1.098 \\
& $(0.030)$ & $(0.121)$ & $(0.079)^{* *}$ & $(0.295)^{* * *}$ \\
1(25 Rebate) & -0.052 & -0.044 & 0.022 & 0.126 \\
& $(0.019)^{* * *}$ & $(0.078)$ & $(0.060)$ & $(0.254)$ \\
1(Information) & -0.014 & -0.160 & 0.029 & 0.181 \\
& $(0.024)$ & $(0.101)$ & $(0.074)$ & $(0.323)$ \\
1(Spiff) & 0.020 & 0.065 & -0.137 & -0.034 \\
& $(0.032)$ & $(0.112)$ & $(0.110)$ & $(0.376)$ \\
1(Spiff and 25 Rebate) & 0.001 & 0.142 & & \\
& $(0.087)$ & $(0.288)$ & & \\
1(Spiff and 100 Rebate) & 0.108 & 0.519 & 0.939 & 3.055 \\
& $(0.138)$ & $(0.490)$ & $(0.263)^{* * *}$ & $(0.711)^{* * *}$ \\
$N$ & 23,338 & 23,338 & 21,613 & 21,699 \\
Dep. Var. Control Mean & .364 & .364 & .009 & .009 \\
Regression Type: & ITT & Scaled & ITT & Scaled \\
& & ITT & & ITT \\
\hline
\end{tabular}

Notes: This table reports probit estimates of Equation (11), as a robustness check to Table 6. The top row lists the column number corresponding to Table 6; columns 2 and 5 cannot be estimated in probit because they use instrumental variables with a binary dependent variable and binary instrument. The sample sizes differ slightly because the probit estimator drops observations with indicators that perfectly predict failure. This drops several $\mu_{a}$ coefficients in all columns and the 1(Spiff and 25 Rebate) indicator in the right two columns. All regressions contain agent and period indicator variables. Robust standard errors in parenthesis. *,**,***: Statistically significant with 90, 95, and 99 percent confidence, respectively. 